\title{
Finite-element analysis of post-tensioned SG-laminated glass beams with mechanically anchored tendons
}

\author{
Chiara Bedon - Christian Louter
}

Received: 29 January 2016 / Accepted: 7 April 2016 / Published online: 26 April 2016

(C) Springer International Publishing Switzerland 2016

\begin{abstract}
Based on past experimental research results, this paper aims to investigate the structural performance of laminated glass beams with posttensioned, mechanically anchored tendons, via extended finite-element (FE) simulations. The posttensioned glass beam concept offers the advantage of providing a certain amount of initial compressive stresses in glass, hence resulting in a marked increase of the initial fracture load and in a rather appreciable redundancy, compared to typically brittle, unreinforced glass beams. Due to the presence of the post-tensioned tendons, a significant level of residual strength can also be guaranteed, thus resulting in a structurally efficient and safe design concept. In order to fully optimize the expected resistance and redundancy potentialities, however, careful consideration should be paid for a multitude of geometrical and mechanical aspects. In this research contribution, both full $3 D$ and shell models are implemented for post-tensioned laminated glass beams. Based on validation of these FE models towards the past full-scale experimental results, the effects of several mechanical parameters are emphasized (e.g. steel tendon percentage, level of the applied pre-stressing force and the presence of possible geo-
\end{abstract}

\footnotetext{
C. Bedon ( $\square)$

University of Trieste, Trieste, Italy

e-mail: bedon@dicar.units.it

C. Louter

TU Delft, Delft, The Netherlands
}

metrical imperfections) under room temperature and quasi-static loads. It is expected, based on the current study, that the examined design concept could be further developed and optimized.

Keywords Post-tensioning - Finite-element investigations - Full-scale experimental validation · Redundancy

\section{Introduction}

The concept of post-tensioning glass beams is targeted at enhancing the initial fracture strength and postbreakage redundancy of structural glass beams that can be applied in the architectural context. These goals are reached by applying a beneficial compressive pre-stress in the glass beams by means of post-tensioning tendons. This compressive pre-stress (partly) annuls the tensile stresses resulting from external action, thereby increasing the initial tensile fracture strength of the glass beam. Additionally, the post-tensioning tendons provide a post-breakage load-carrying mechanism by bridging the cracks that occur upon fracture of the glass. As such, the concept of post-tensioned glass beams has strong similarities with reinforced and posttensioned concrete technology and has links with earlier studies into reinforced glass beams (Martens et al. 2015a,b). 
Academic studies, yet small in number, are investigating the principle of post-tensioned glass beams. Different post-tensioning strategies are explored, such as tendons integrated within the beam web such as (Bos et al. 2004; Louter et al. 2014), or tendons placed externally such as (Díaz et al. 2011). Also, distinction can be made between tendons placed linearly along the beam web, or tendons that are placed such that they provided an uplift to the beam (Weller and Engelmann 2014; Jordão et al. 2014). Finally, post-tensioning strategies with either unbonded tendons that are mechanically anchored at the beam ends, or with tendons that are adhesively bonded along the length of the beam are investigated (Louter et al. 2014). In the latter case, the tendons are adhesively bonded to the glass while being under pre-tension and released upon full curing of the adhesive. Apart from academic studies into post-tensioned glass beams, also a real-world application is realized in which $6.2 \mathrm{~m}$ span post-tensioned glass beams are applied in a roof structure (Schober et al. 2004). A recent overview and review of experimental research on post-tensioned glass beams, along with a review of reinforced glass beams and posttensioned glass beams, is provided in Martens et al. (2015a,b).

Most studies into post-tensioned glass beams are mainly experimental of nature and are aimed at providing an experimental validation of the beam concept. The current paper, however, focuses on an FE-analysis of post-tensioned glass beams and builds on the experiments described in Louter et al. (2014) concerning post-tensioned glass beams with unbonded mechanically anchored stainless steel tendons. The goal of the current paper is to provide a parametric FE study related to the global structural performance of the examined structural typology, including the effects of several mechanical and geometrical parameters like the steel tendon percentage, the level of applied prestressing force and possible initial geometrical imperfections. This is achieved by adopting the specimen geometry of the aforementioned experimental study and analyzing it through full 3D solid or geometrically simplified FE numerical models implemented in the ABAQUS/Standard software (Simulia 2016). As a first stage of an ongoing research study, based on the available full-scale experimental results, room temperatures only are taken into account, hence resulting in a specific mechanical calibration of the specimens components (the SG foils, in particular).

\section{Design concept and literature background}

\subsection{Available experimental studies}

For the current FE exploratory investigations, the experimental specimens presented in (Louter et al. 2014) were considered.

The typical cross-section of the examined laminated glass beams with post-tensioned, mechanically anchored tendons is shown in Fig. 1. Three specimens, $L=1500 \mathrm{~mm}$ long and $H=125 \mathrm{~mm}$ high but with a specific pre-stressing level, were tested for each geometrical configuration. Each beam consisted, in particular, of three layers of annealed float glass (with 6$10-6 \mathrm{~mm}$ the nominal thicknesses respectively) bonded together by means of $1.52 \mathrm{~mm}$ thick SentryGlas ${ }^{\circledR}(\mathrm{SG})$ interlayer sheets. The inner glass layer $(h=105 \mathrm{~mm})$ was recessed along both the top and bottom edges. The long edges of all glass layers were polished before lamination, whereas the short edges at the beam ends were polished after lamination to guarantee a perfect alignment of the glass where the post-tensioning forces were introduced at a later stage (Louter et al. 2014). The applied tendons were stainless steel threaded bars with $\phi_{t}=8 \mathrm{~mm}$ (T8 beam types, in the following) and $10 \mathrm{~mm}$ (T10) the nominal diameter respectively, grade 1.4301 , integrated at the recessed beam edges (with $d_{c}$ representative of the distance between the middle axis of each tendon and the laminated glass (LG) section, while $d_{\text {gap }}$ is the distance between the glass beam top/bottom surface and the tendon external surface, see Fig. 1).

The post-tensioning forces $P_{0}$ were applied at the beam ends by means of steel end pieces at which the steel tendons were anchored. On one end of the beam, the tendons were extended by means of hydraulic jacks connected to a manually operated hydraulic pump. On the other end, the force in the tendons was monitored by means of load cells through which the tendons were fed. Once the required post-tensioning force was obtained, the tendons were anchored with screw nuts, and the hydraulic jacks were released and removed.

After post-tensioning, all the beams were tested in four-point bending, see Fig. 2, by means of a universal tension-compression machine (Zwick 500kN). Lateral supports were also provided, to ensure possible out-ofplane deformations of the specimens. During the experiments, a constant displacement rate of $1 \mathrm{~mm} / \mathrm{min}$ was applied to the beams up to first glass fracture. Subse- 


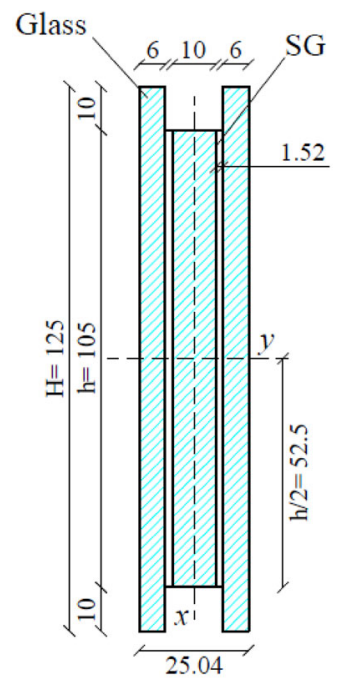

(a)

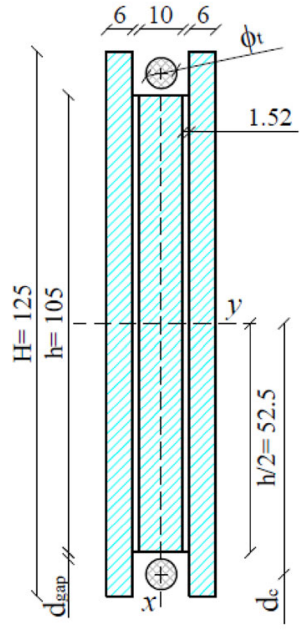

(b)
Fig. 1 Schematic cross-sectional geometry for the examined a unreinforced and $\mathbf{b}$ post-tensioned beams with mechanically anchored tendons (Louter et al. 2014). Nominal dimensions in millimetres (polished edges neglected)

quently, in the post-cracked stage, the displacement rate was increased up to $2-5 \mathrm{~mm} / \mathrm{min}$. Overall, the average duration of each experiment amounted to about 3045 minutes. During the test, the applied force $(F)$ and machine displacement were measured and recorded. The full description of the test methods and results can be found in (Louter et al. 2014).

\subsection{Post-tensioned glass design concept}

The primary beneficial effect of an initial pre-stress, for the beam typology recalled in Sect. 2.1, manifests in an average uniform state of compressive stresses in the glass layers (at a certain distance from the beam ends, i.e. $\geq \approx 100 \mathrm{~mm}$ in this study, see Fig. 7) equal to:

$\sigma=-\frac{P_{0}}{A_{\text {glass }}}$

where $P_{0}$ denotes the total pre-stressing load assigned to the top/bottom tendons together and $A_{\text {glass }}$ represents the total cross-sectional glass surface of the nominal LG beam $\left(A_{\text {glass }}=2550 \mathrm{~mm}^{2}\right.$, in the current study).

For the test setup proposed in Fig. 2, in particular, the effect of post-tensioning is emphasized when the external load $F$ is applied to a given beam geometry, e.g. with:

$\sigma_{M, t o p}=-\frac{a \frac{F}{2} \frac{h}{2}}{I_{y}}$ and
$\sigma_{M, \text { bottom }}=\frac{a \frac{F}{2} \frac{h}{2}}{I_{y}}$

denoting the bending principal stresses expected at the mid-span top / bottom glass edges respectively, while:

$\sigma_{\text {tot }, \text { bottom }}=-\frac{P_{0}}{A_{\text {glass }}}+\frac{a \frac{F}{2} \frac{h}{2}}{I_{y}}$ and

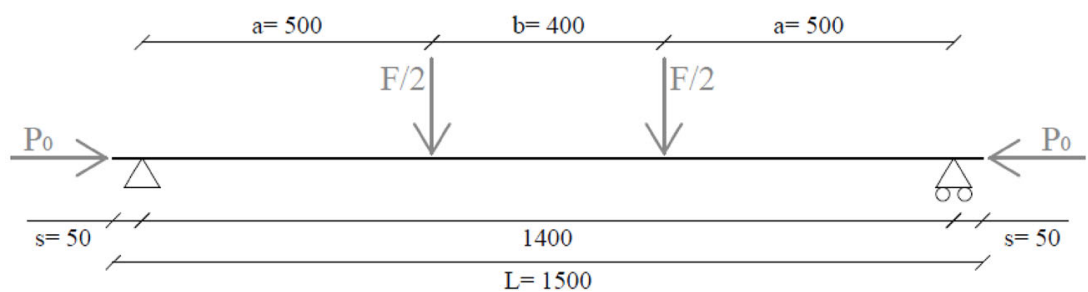

(a)

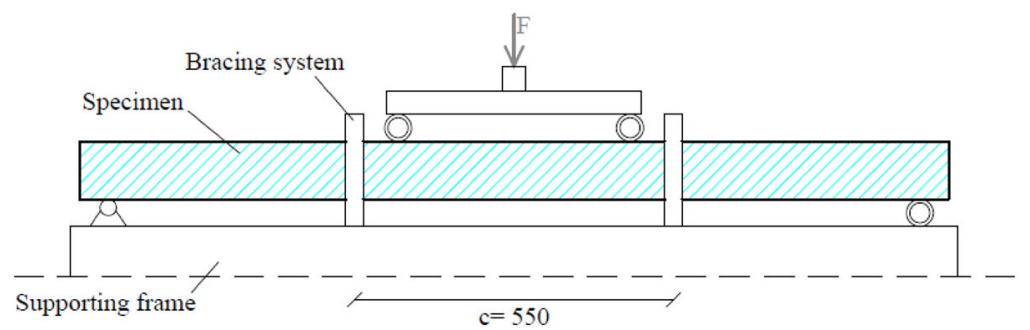

(b)

Fig. 2 Four-point bending test setup (Louter et al. 2014). a Reference configuration and b schematic representation of the test setup (front view). Nominal dimensions in millimetres 
Fig. 3 Overview of the fully $3 \mathrm{D}$ reference model (ABAQUS/Standard). a Front view, b transversal cross-section. Nominal dimensions in millimetres

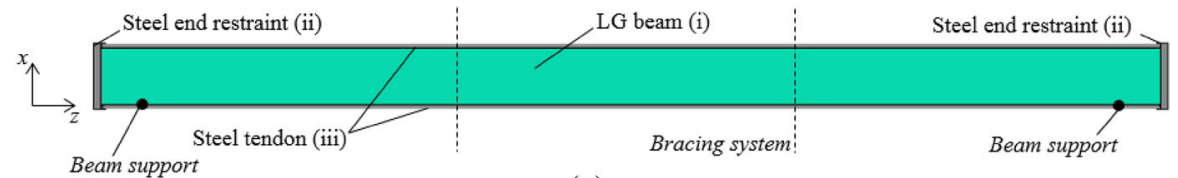

(a)

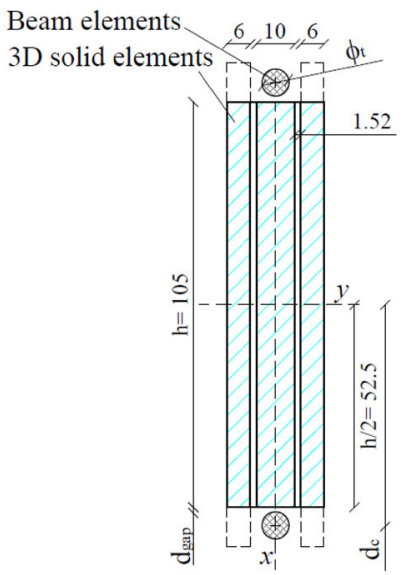

(b) $\sigma_{\text {tot }, \text { bottom }}=-\frac{P_{0}}{A_{\text {glass }}}-\frac{a \frac{F}{2} \frac{h}{2}}{I_{y}}$

represent the total effect due to post-tensioning and bending moments, with $I_{y}$ the second moment of area around the strong axis.

\section{Finite-element (FE) methodology}

\subsection{General FE approach}

Based on the experimental investigations discussed in (Louter et al. 2014), the purpose of the current research contribution is an exploratory, parametric FE study aimed to further assess the structural performance of this design concept.

\subsection{Solving method}

Through the FE study, the investigations took the form of parametric geometrically nonlinear, static incremental, load-controlled simulations (ABAQUS/Standard) consisting of two separate steps. In the first step (I) a given initial pre-stress $P_{0}$ only was assigned to the steel tendons, after which a four-point bending test was simulated by applying linearly increasing vertical loads $F / 2$ in the second step (II), in accordance with the test setup of Fig. 2.

\subsection{Geometry and mechanical interactions}

The FE modelling approach was properly calibrated, so that the accuracy as well as the computational efficiency of the parametric simulations could be guaranteed.

In this sense, the first reference FE model, as schematically presented in Fig. 3, consisted of (i) a LG cross-section and (ii) special end steel restraints fully composed of 8-node, 3D solid glass elements (C3D8R, linear brick, reduced integration with hourglass control elements). The two steel tendons (iii), conversely, were described in the form of 2-node beams elements (B31 type).

The basic assumptions of the full modelling approach were established on the base of few key aspects. Based on the nominal physical section provided in Fig. 2, the position of the steel tendons along the beam height was kept fixed (i.e. with $2 d_{c}=115 \mathrm{~mm}$ the distance between the middle axis of the two tendons, see Fig. 3).

For the LG beam, the nominal thickness, length and width was taken into account for each glass/SG layer respectively (Fig. 3). The LG layers were described by means of internal partitions, i.e. in the hypothesis of a fully rigid connection at the glass-to-SG interface and fully neglecting any possible delamination effect. In this geometrical description of the beam cross-section, the exception was represented by the external glass 


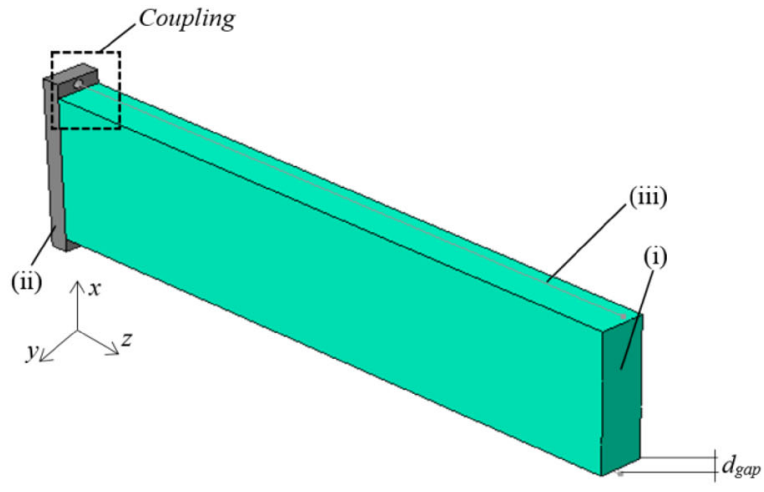

(a)

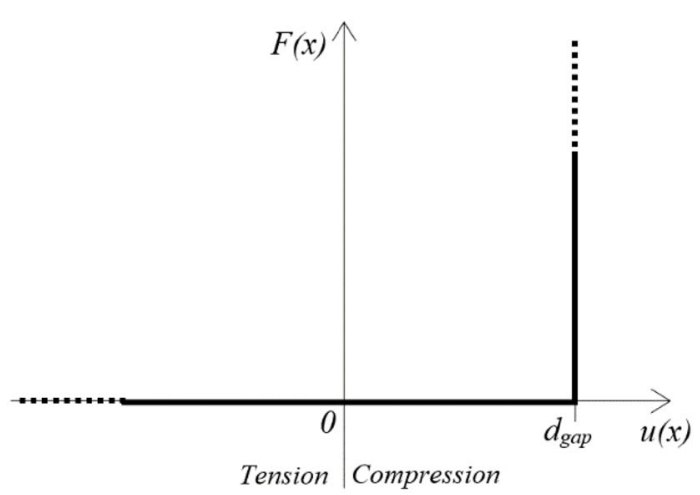

(c)

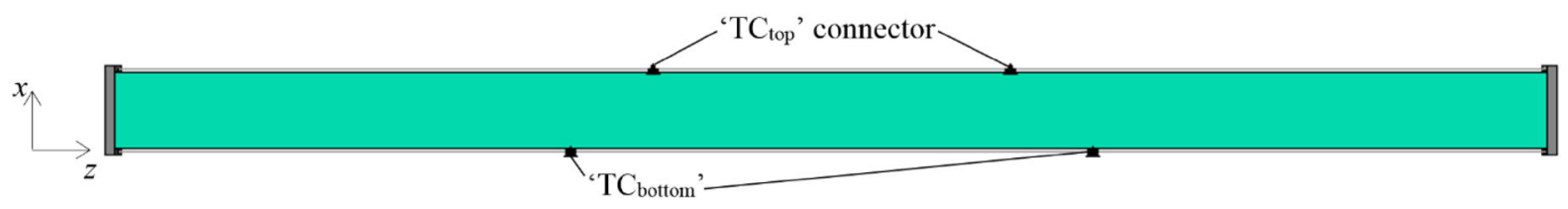

(b)

Fig. 4 Overview of the fully 3D reference model (ABAQUS/Standard). a Detail of the end restraints (axonometry); b point mechanical connectors (front view) and constitutive law for the ' $\mathrm{TC}_{\text {bottom }}$ ' mechanical connectors

sheets, where the small portions of glass exceeding the inner glass ply geometry were neglected and a total height $h=105 \mathrm{~mm}$ was taken into account, hence resulting in a total $105 \times 22 \mathrm{~mm}^{2}$ glass section (with $25.04 \mathrm{~mm}$ the thickness of the full LG cross-section). This assumption was considered reasonable, from a mechanical point of view, and computationally effective for FE modelling purposes. In order to provide appropriate reproduction of the actual bending stiffness $E_{g} I_{y}=2.04 \times 10^{11} \mathrm{~N} / \mathrm{mm}^{2}$ of the beam physical cross section (with $E_{g}=70 \mathrm{GPa}$ for glass (EN 572-2 2012) and $I_{y}=2.92 \times 10^{6} \mathrm{~mm}^{4}$ the second moment of area about the strong axis of the physical glass section), however, a corrected Young's modulus for glass $E_{g}^{*}$ was taken into account. This $E_{g}^{*}$ value was calculated so that the $105 \times 22 \mathrm{~mm}^{2}$ rectangular section of Fig. 3 could offer the same in-plane bending stiffness $E_{g} I_{y}$ of the physical glassy section, based on a material correction factor $c_{g, y}$, that is:

$E_{g}^{*}=c_{g, y} \frac{E_{g} I_{y}}{I_{y}^{*}}$,

with $I_{y}^{*}=2.12 \times 10^{6} \mathrm{~mm}^{4}$ and $c_{g, y} \approx 1.37$.

Regarding the steel tendons, a circular cross-sectional profile with $\phi_{t}$ the nominal diameter of the T8 and T10 experimental tendons was taken into account for the beam elements.
Careful consideration was then paid for the appropriate interaction between the specimen components, in order to avoid any possible misleading effect during both the Steps I and II of each simulation (Fig. 4).

At the interface between (i) the LG end sections and (ii) the corresponding steel supports, a fully rigid connection was reasonably assumed (e.g. 'tie' restraint enabling any possible relative translation or rotation between them). At the interface between (ii) the steel end supports and (iii) the tendons ends, a kinematic 'coupling' constraint was used, so that a fully rigid connection could be taken into account for the anchoring of the cables (Fig. 4a).

The accurate simulation of the physical interaction between (i) the LG beam and (iii) the steel tendons, conversely, was attained by means of local mechanical connectors available in the ABAQUS/Standard library. For the top tendon, two point supports were considered (see Fig. 4b, 'TCtop' connectors). A 'cartesian' translational connector section was used, thereby allowing relative displacements along the $z$-longitudinal axis of the beam/tendon (e.g. during the application of pre-tension forces) but avoiding any possible relative displacement along the vertical $(x)$ direction.

For the bottom tendon, an almost comparable mechanical interaction was used at the interface with 


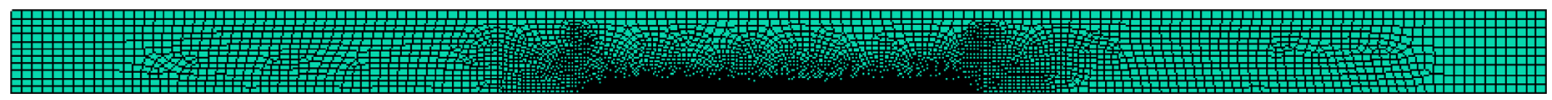

Fig. 5 Overview of the typical mesh pattern for the 3D reference model (ABAQUS/Standard)

the beam bottom surface (see Fig. 4b, 'TCbottom'). However, a different calibration of the 'cartesian' translational connector was taken into account. In this latter case, the tendon is in fact initially detached from the LG beam bottom face. In the case a positive bending moment is applied to the specimen, as in the current research study, the contact between them can occur only once the LG beam itself has attained a certain flexural deformation, e.g. a maximum vertical displacement $u(x)$ at least equal to the distance $d_{\text {gap }}$ between the tendon surface and the beam bottom face (see Figs. 3, 4). In the $z$ direction, any possible relative displacement was allowed, as in the case of the top tendon. Concerning the vertical $(x)$ direction, conversely, a non-linear constitutive law was assigned to the same connector section (see Fig. 4c). The physical effect of the so calibrated connectors resulted in a free deformation of the bottom tendon/beam during the first loading phase (i.e. as far as the LG beam was attaining maximum bending deformations within $\left.d_{\text {gap }}\right)$. Once the first contact between the bottom face and the tendon occurred $\left(u(x) \geq d_{\text {gap }}\right)$, conversely, the point mechanical connectors were activate to work as fully rigid compressive restraints between them. As a result, any possible overlapping between the beam and the bottom tendon was properly avoided for all loading stages of Step II, up to collapse of the specimen.

Concerning the relative displacements and rotations of the tendons and the beam deriving from any possible out-of-plane deformation of the examined specimens, finally, a fully rigid elasticity was taken into account for both the $\mathrm{TC}_{\text {top }}$ and $\mathrm{TC}_{\text {bottom 'cartesian' connectors (i.e. }}$ null relative displacements along the $y$ direction, due to the presence, in the physical beams, of the recessed external glass layers). A 'rotation' connector was also assigned to the same connectors, so that the tendons could follow the overall deflection of the beam. While these FE assumptions could be disregarded for pure in-plane bending simulations (i.e. due also to the presence of out-of-plane bracing systems in the test setup of Fig. 2), the structural analysis of the same beams under different loading and boundary configurations should in fact properly take into account the related effects.

\subsection{Mesh}

A primary role was also assigned to the mesh pattern, in the so assembled FE models. Figure 5 presents a typical front view for the analyzed beams. In accordance with (Bedon and Louter 2014), a free meshing technique with advancing front algorithm was defined. Local mesh seeds and sup-partitioning portions for the LG beam were taken into account, so to optimize the size/number of brick elements were glass cracking was expected. A preliminary mesh sensitivity study was in fact carried out (i.e. including the maximum size of brick elements and the number of elements through the thickness of each layer), in order to ensure the accuracy of the obtained results but the computational efficiency of the so assembled FE models. As a result, a fine mesh pattern was assigned especially to the central portion of the beam, e.g. where the tensile cracks were expected (with $l_{\min }=2 \mathrm{~mm}$ the minimum characteristic size for the brick elements along the bottom edge of glass). The maximum size of brick elements in the external portions of the beam, conversely, was set equal to $l_{\text {max }}=40 \mathrm{~mm}$.

Through the thickness of the beam, moreover, one element only was used for the discretization of each glass/SG layer. Compared to the mesh assumptions discussed in (Bedon and Louter 2014), where dynamic simulations with quasi-static application of loads were carried out, this efficient modelling choice was justified by the adopted solving method (e.g. static simulations not sensitive to possible inertial phenomena, like in the case of dynamic simulations discussed in Bedon and Louter 2014).

The so implemented mesh pattern for the LG beam only resulted in approximately 26,000 brick elements $(\approx 28,000$ elements and $\approx 105,000$ DOFs for the full assembly), that is in a rather computationally efficient FE model able to provide a qualitatively realistic description of tensile cracks in glass, but at the same 
time to preserve the computational cost of each simulation.

\subsection{Loads and boundaries}

The four-point bending test setup discussed in (Louter et al. 2014), see Fig. 2, was properly reproduced in the implemented FE models. Each LG beam was simply supported at its bottom face (with $50 \mathrm{~mm}$ the distance of each support from the beam ends). Additional bracings were defined in the form of $u_{y}$ translational restraints, for the beam nodes lying at a distance of $475 \mathrm{~mm}$ from the beam ends (see Fig. 2).

The initial pre-stress force $P_{0}$ (Step I) was assigned to the steel top and bottom tendons in the form of linearly increasing bolt loads. Additional linearly increasing point loads $F / 2$ were assigned to the beam top surface, at a distance of $500 \mathrm{~mm}$ from the supports, to simulate the four-point bending experimental setup (Step II).

\subsection{Materials}

Careful consideration was paid for the mechanical characterization of materials. For the stainless steel representative of the top and bottom tendons, an isotropic, idealized elasto-plastic constitutive model was used, with $E_{s}=200 \mathrm{GPa}$ the Young's modulus, $v_{s}=0.3$ the Poisson's ratio, $\sigma_{y, s}=\sigma_{u, s}=640 \mathrm{MPa}$ the yielding/failure stress. The yielding/failure input parameters for the stress-strain relationship were derived from tensile experimental tests carried out on small tendon specimens, with $\sigma_{y, s}=\sigma_{u, s}$ the stress value corresponding to their failure tensile load (see Louter et al. 2014 for further details). An indefinitely linear elastic and isotropic material $\left(E_{s}=200 \mathrm{GPa}, v_{s}=0.3\right)$ was assigned to the steel devices representing the beam end restraints. For SentryGlas, for the purpose of the current FE investigations, an equivalent, fully linear elastic mechanical behaviour was taken into account. The elastic stiffness $\left(E_{S G}=120 \mathrm{MPa}\right)$ was calibrated on the base of the average duration of the experiments $(\approx 30-45$ minutes) and past literature contributions (see for example Callewaert et al. 2012; Louter and Nielsen 2013; Bedon and Louter 2014). An almost null sensitivity of the predicted results was found to the $E_{S G}$ value, within the temperature and time loading range of interest for the current study. An extended FE study of the same beam typology under variable loading and ambient configurations, however, should take into account a more detailed mechanical calibration of the SG foils, due especially to the strong sensitivity of their structural performance to high temperatures as well as to possible failure mechanisms occurring in them (Larcher et al. 2012; Ferretti et al. 2012; Franz 2015; Trösch 2015; Ringli and Vogel 2016).

Finally, glass was described by means of the 'concrete damaged plasticity' model ('CDP', in the following) available in the ABAQUS/Standard materials library. This assumption resulted in an equivalent, homogeneous and isotropic material having brittle elastic behaviour, up to failure, with $E_{g}^{*}=c_{g, y} \times E_{g}$ (see Sect. 3.2) and $v_{g}=0.23$ the Young's modulus and Poisson's ratio (EN 572-2 2012). Careful consideration was paid to the mechanical calibration of the postcracked behaviour, both in tension and compression, in order to reproduce the desired mechanical responses. The 'CDP' mechanical model, originally implemented for reinforced concrete components, well applies in fact to materials with quasi-brittle behaviour such as glass or masonry. Recent FE examples of application of this damage model to masonry structural systems can be found in (Pandey and Bisht 2014; Xiong et al. 2014; Gattesco et al. 2015 etc.). In the CDP model, the yield surface function takes the form of an extended Drucker-Prager classical model and is based on the proposal of Lubliner et al. (1989), successively modified in accordance with (Lee and Fenves 1998) to take into account different evolution of strength under tensile and compressive stresses. The inelastic compressive and tensile behaviours are described in the form of a multi-hardening plasticity and a scalar isotropic damaged elasticity characteristic curves (Fig. 6). For the full theoretical background, extended details can be found in the ABAQUS Theory Manual. In this work, the main post-cracked input parameters were defined in accordance with earlier research contributions and literature references (see Annex I). The characteristic tensile resistance value, specifically, was preliminary set equal to $\sigma_{R k, t}=45 \mathrm{MPa}$ [e.g. annealed glass (EN 5722 2012)]. It should be noted that the actual strength of the glass edge is likely to deviate from this here applied value due to several parameters such as edge treatment, size effects, loading rate and others. These aspects are, however, outside the scope of the current study and more details can be found in (Vandebroek et al. 2012). Concerning the compressive resistance of glass, a con- 


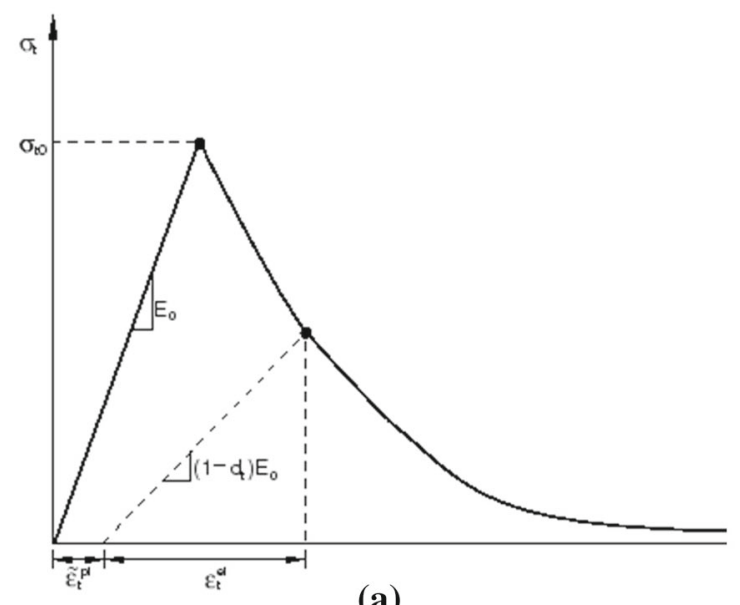

(a)

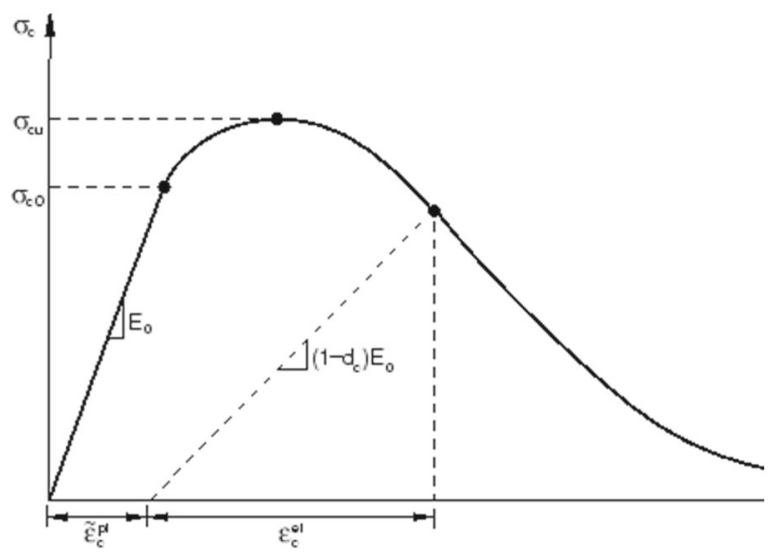

(b)

Fig. 6 Mechanical constitutive law for the CDP model in a tension and $\mathbf{b}$ compression (ABAQUS/Standard)

ventional reference value $\sigma_{R k, c}=1000 \mathrm{MPa}(\mathrm{CNR}-$ DT 210/2013 2013) was taken into account, so that the performance of the beams (post-breackage load levels, in particular) could be properly investigated.

\section{Discussion of 3D FE results}

\subsection{Validation of the reference FE model}

First, the FE model described in Sect. 3 was validated towards the full-scale experimental results available for the T8 and T10 specimens.

A total average pre-stressing force of $50 \mathrm{kN}$ was assigned - equally distributed - to the T8 and T10 steel tendons, based on the average test measurements collected in Table 1. For the examined FE models, the effect of post-tensioning resulted (with the exception of the portions of the beam close to the end restraints) in an initial state of uniform compressive stresses in glass equal to $-18 \mathrm{MPa}$, i.e. in rather close agreement with the corresponding test measurements (with $-19 \mathrm{MPa}$ the expected experimental value). The typical distribution of these compressive stresses, in the glass layers only, is proposed in Fig. 7a for the T8 beam (end of Step I).

Despite the geometrical and mechanical assumptions of the implemented reference FE models (Sect. 3), rather accurate estimations of initial stresses in the glass section were obtained. This aspect can be observed from Fig. 7b, where a detailed contour plot of initial compressive stresses is proposed for the typical FE model object of investigations and a refined FE model able to take into account the nominal geometrical (i.e. physical cross-section given in Fig. 3) and mechanical features of the experimental specimens.

Through the parametric study, the structural response of the $\mathrm{T} 8$ and $\mathrm{T} 10$ examined beams was critically investigated by taking into account several influencing parameters, e.g. the overall load-deflection response as well as some further factors well representative of the key steps of their responses (e.g. configuration of first glass cracking; in-plane elastic stiffness; ultimate resistance and displacement; failure mechanism; crack opening and propagation, etc.).

Some comparisons are depicted in Fig. 8, in the form of applied load $F$ vs vertical deflection at mid-span $u_{\text {max }}$, for both the T8 and T10 beams. There, the numerically calculated $F-u_{\max }$ responses are compared with the corresponding experimental results (Louter et al. 2014), as well as with the numerical response of a 'reference' glass beam without any post-tensioning system (i.e. unreinforced laminated glass geometry of Fig. 1a).

In general, by comparing the ABAQUS and experimental curves it can be seen that the numerical curves approximate the experimental curves relatively well. However, also some deviations can be seen. Firstly, an offset between the experimental and numerical curves can be seen. This offset is explained by initial settlements in the experimental test setup, which are evidently not incorporated in the numerical results. Sec- 

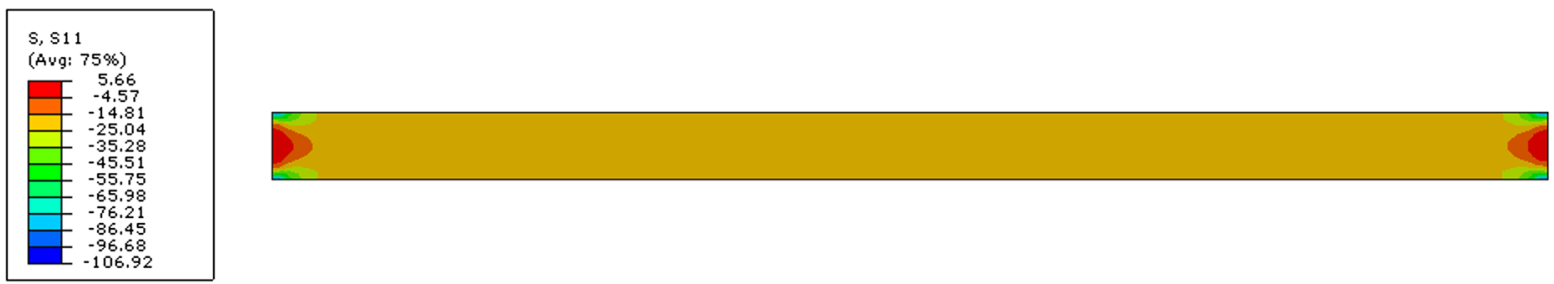

(a)

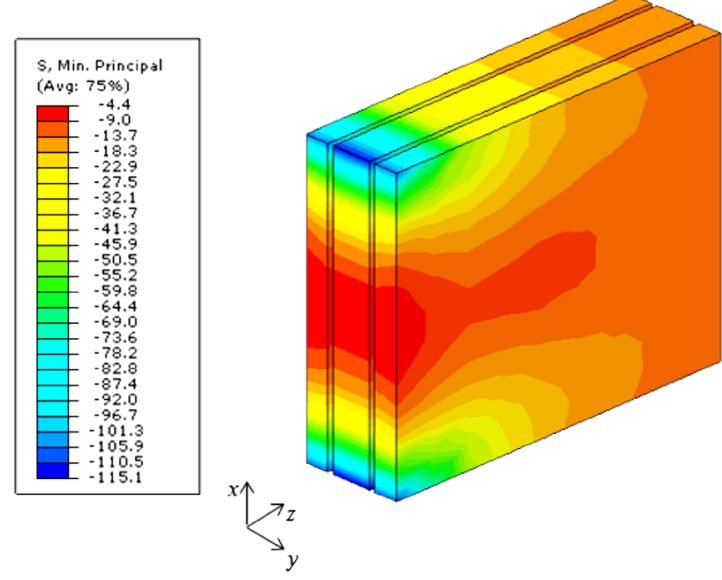

Reference FE model

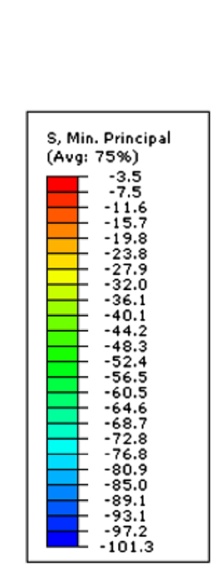

(b)

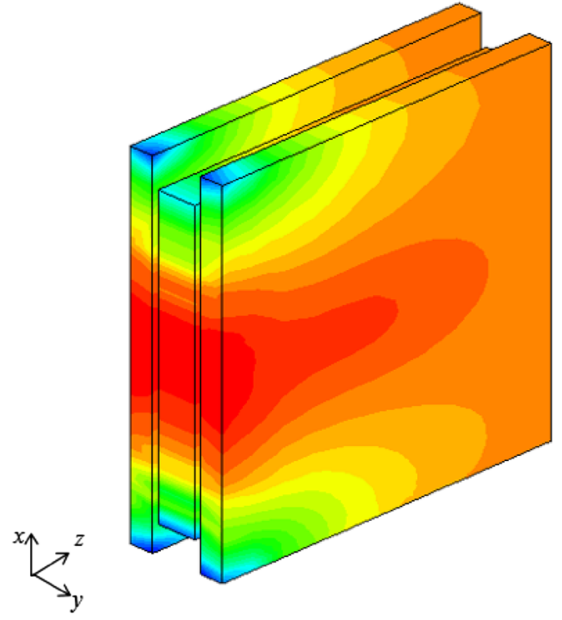

Refined FE model
Fig. 7 a Numerically calculated initial compressive stresses in glass due to $P_{0}$ (values in [MPa]), example proposed for the T8 beam (front view) and $\mathbf{b}$ validation of the so predicted stresses in

ondly, in the case of the T8 beam, a partial overestimation was found in terms of ultimate resistance, e.g. with a percentage discrepancy of $+5.3 \%$. This effect can be partly justified by the assumption of a nominal cross-sectional area for the T8 tendons, e.g. by the slight overestimation of the actual resisting transversal cross-section for the experimentally used tendons. Finally, the FE models typically highlighted a more pronounced drop and post-cracked stiffness after the opening and propagations of first cracks in glass.

From both the T8 and T10 beam results, it can be in fact seen that the obtained $F-u_{\max }$ curves are characterized by distinct phases.

In more detail, at the first stage of the bending phase (see for example Fig. 8a, point $s_{1}$ ), the post-tensioned beams behave linear elastically. The effects of first glass cracking can be mainly noticed in terms of a slight deviation of the $F-u_{\max }$ plots from their original slope glass towards a refined FE model (ABAQUS/Standard, detail in the vicinity of the load application)

$\left(s_{2}\right)$. The post-cracked stage $\left(s_{3}\right)$ is then governed by the beneficial contribution of the bottom steel tendons only. As far as the bottom tendons do not yield, the beams are able to sustain an appreciable residual load as well as to attain large displacements. At this stage, major discrepancies can be found between the FE estimations and the corresponding experimental predictions. This effect can be justified both by the mechanical calibration of the SG layers (i.e. crack bridging contributions not take into account by the actual FE models (see also Louter and Nielsen 2013) as well as by the mechanical interaction assigned to the beams and the tendons. As far as the first cracks in glass open, both in the case of the T8 and T10 beams the bottom tendons are not in contact with glass. The cracked glass beams, consequently, are able to undertake a certain deflection before the physical contact with the bottom tendons occur. The bottom tendons themselves provide then a 
Fig. 8 Experimental (Louter et al. 2014) and numerical

(ABAQUS/Standard) load-displacement response for the $\mathbf{a}$ T8 and $\mathbf{b} \mathrm{T} 10$ beams with mechanically anchored tendons, compared to the unreinforced reference beam ('ABAQUS-No tendons' and 'TEST-No tendons' curves)

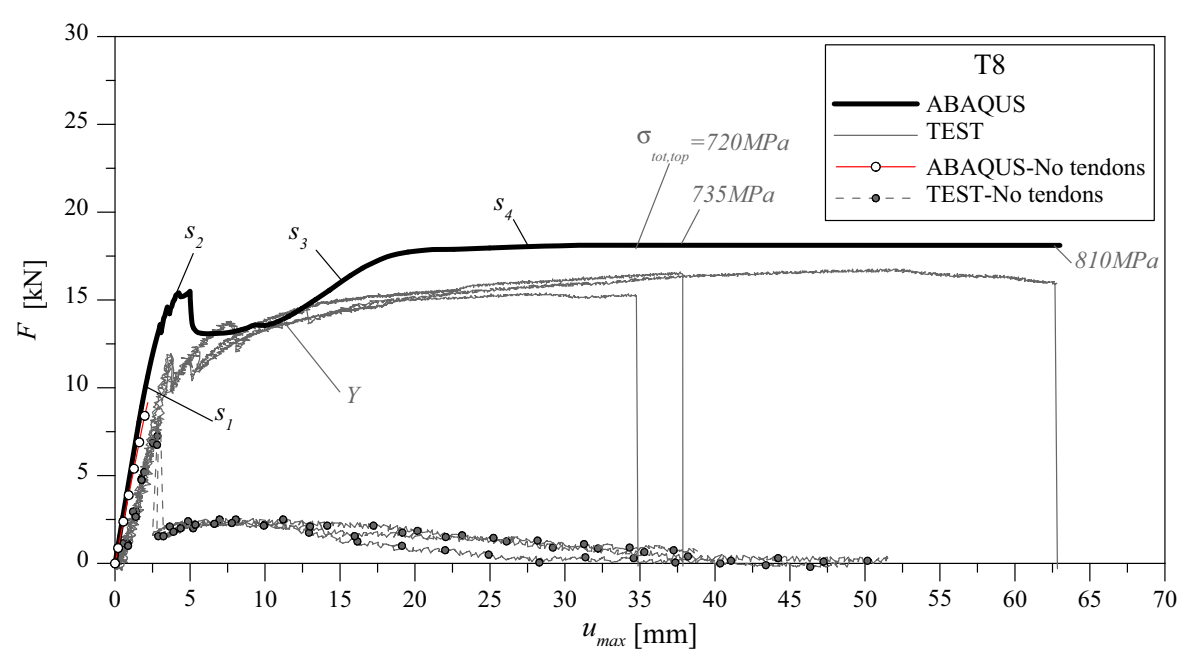

(a)

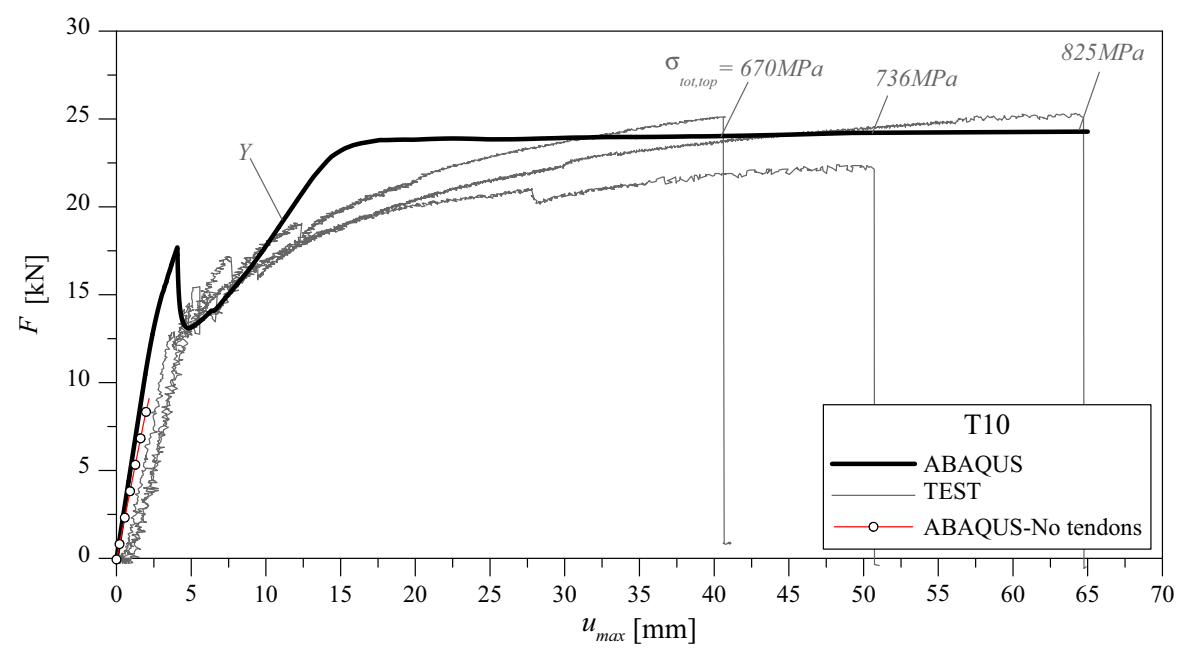

(b) certain post-cracked residual stiffness and resistance up to collapse.

At the conclusive stage of the FE simulations, $\left(s_{4}\right)$, the beams collapse in fact due to compressive cracking at the glass top edge or rupture of the bottom tendons. In order to better explore the collapse mechanism for the examined beams, Fig. 8 highlights in the post-cracked stage some additional key points. The grey italic labels ' $\sigma_{\text {tot, top }}$, specifically, are representative of the maximum compressive stress along the top glass edge, associated to a maximum mid-span beam deflection $u_{\max }$ corresponding to the failure deflection of the full-scale experimental specimens. As shown, an average compressive resistance of glass equal to $\approx 740 \mathrm{MPa}$ was indirectly derived from the $F-u_{\max }$ experimental mea- surements, i.e. in the order of $\approx 16.5$ times the nominal tensile resistance. The ' $Y$ ' grey label, conversely, represents the first attainment in the bottom tendons of a maximum principal stress exceeding the yielding stress of the tendons themselves. The limit yielding stress was first attained in the bottom tendons at about 11-12 mm of mid-span vertical deflection.

In terms of pre-cracking and post-cracked residual performances of the T8 and T10 beams, a rather close agreement was found between the FE numerical estimations and the corresponding experimental measurements. In Table 1, some comparative results are proposed for both beam typologies, in the form of main output parameters associated to the first cracking performance and post-cracked residual strength/ 
Table 1 Experimental (Louter et al. 2014) and numerical (ABAQUS/Standard) results for the T8-T10 specimens and for the reference unreinforced specimens

\begin{tabular}{llllll}
\hline Beam type & Exp./FE & $\begin{array}{l}\text { Pre-stress } \\
\text { load } P_{0}(\mathrm{kN})\end{array}$ & $\begin{array}{l}\text { Fracture } \\
\text { load } F_{1}(\mathrm{kN})\end{array}$ & $\begin{array}{l}\text { Fracture } \\
\text { displacement } \\
u_{1}(\mathrm{~mm})\end{array}$ & $\begin{array}{l}\text { Maximum } \\
\text { post-fracture } \\
\text { load } F_{u}(\mathrm{kN})\end{array}$ \\
\hline T8 & Avg. Exp.(\#1, \#2,\#3) & 50.0 & 11.6 & 3.10 & 16.3 \\
& ABAQUS & & 12.2 & 2.45 & 17.6 \\
T10 & Avg. Exp. (\#1, \#2, \#3) & & 12.8 & 3.26 & 22.6 \\
& ABAQUS & - & 14.0 & 2.66 & 2.9 \\
No tendons & Avg. Exp. (\#1, \#2, \#3) & - & 8.0 & 3.01 & $\mathrm{n}$ \\
& ABAQUS & - & 8.7 & 2.09 & \\
\hline
\end{tabular}

redundancy. There, $F_{1}$ and $u_{1}$ denote the vertical load and deflection associated to first glass cracking, respectively. A general close correlation was found for the compared beam typologies, as shown. The exception was represented by the reference specimen without tendons, which exhibited a minimum residual resistance that the corresponding FE model was not able to capture (see Table 1 and Fig. 8a, "ABAQUS-No tendons" and "TEST-No tendons" curves).

\subsection{Failure mechanism and crack pattern}

In terms of cracking mechanism for the same beams, the collapse of the T8 and T10 models occurred due to the progressive propagation of a major tensile crack in glass (see for example Fig. 9). A subsequent progressive yielding of the bottom steel tendon, combined with crushing mechanisms at the glass top edge (e.g. with maximum compressive peaks in the beam crosssections affected by major tensile cracks), was noticed in the post-cracked stage.

An overall structural performance in rather close agreement with the corresponding experimental specimens was generally observed (see Fig. 9 and Louter et al. 2014), despite the geometrical and mechanical simplifications of the implemented FE models.

Through the bending phase, an almost uniform propagation of cracks through the glass layers was in fact noticed, as in the case of the full-scale specimens (Louter et al. 2014) but also in accordance with past numerical studies dedicated to the mechanical performance of structural glass beams of various typologies (Louter and Nielsen 2013; Bedon and Louter 2014; Martens et al. 2015a, b). In Figs. 10 and 11, some comparative plots are proposed for the $\mathrm{T} 8$ beam presented in Fig. 8a. These plots, representative of the qualitative tensile damage propagation in the glass layers, provide evidence of the progressive crack opening in glass, as a function of the mid-span beam deflection $u_{\max }$. In them, the same 'box detail' of Fig. 9a is shown (being the top of the beam in compression), where blue is representative of fully uncracked glass.

As shown in Fig. 10, despite a constant mesh pattern was used through the thickness of the beams for all the glass and SG layers, small cracks first propagate separately in each glass ply (see the contour plots for G1, G2 and G3 layers at $u_{\max }=3.70 \mathrm{~mm}$ ). As far as the applied bending loads increase, however, few major cracks with almost a uniform distribution through all the glass plies were found (see the plots proposed for $u_{\max }=34.67 \mathrm{~mm}$ ).

\section{Parametric FE study}

An exploratory, FE parametric study was then carried out on the examined beam typology, so that practical information could be obtained. Careful consideration was paid for several aspects, including the steel tendons diameter, the level of pretension force, as well as the possible effect of initial geometrical imperfections.

\subsection{Steel tendon section}

For the FE models geometrically and mechanically described in Sect. 3 and Fig. 3, the effects due to variation of the steel tendons cross-section were first taken into account. In doing so, the same initial precompressive force $P_{0}=50 \mathrm{kN}$ was assigned to the tendon, while gradually increasing the nominal diameter $\phi_{t}$. The so obtained results are provided in Fig. 12, 


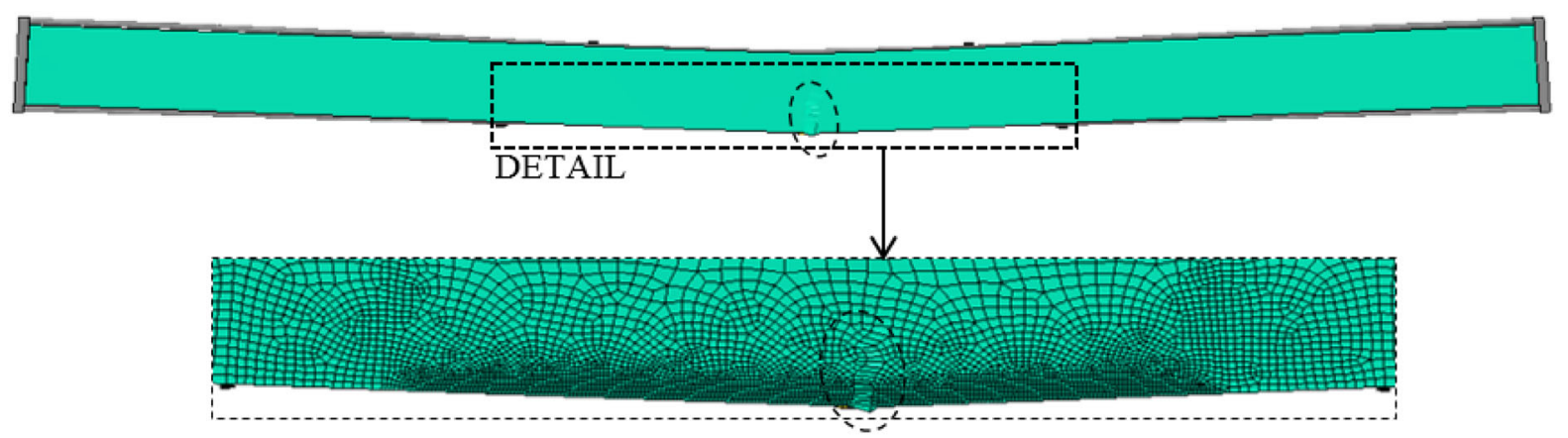

(a)

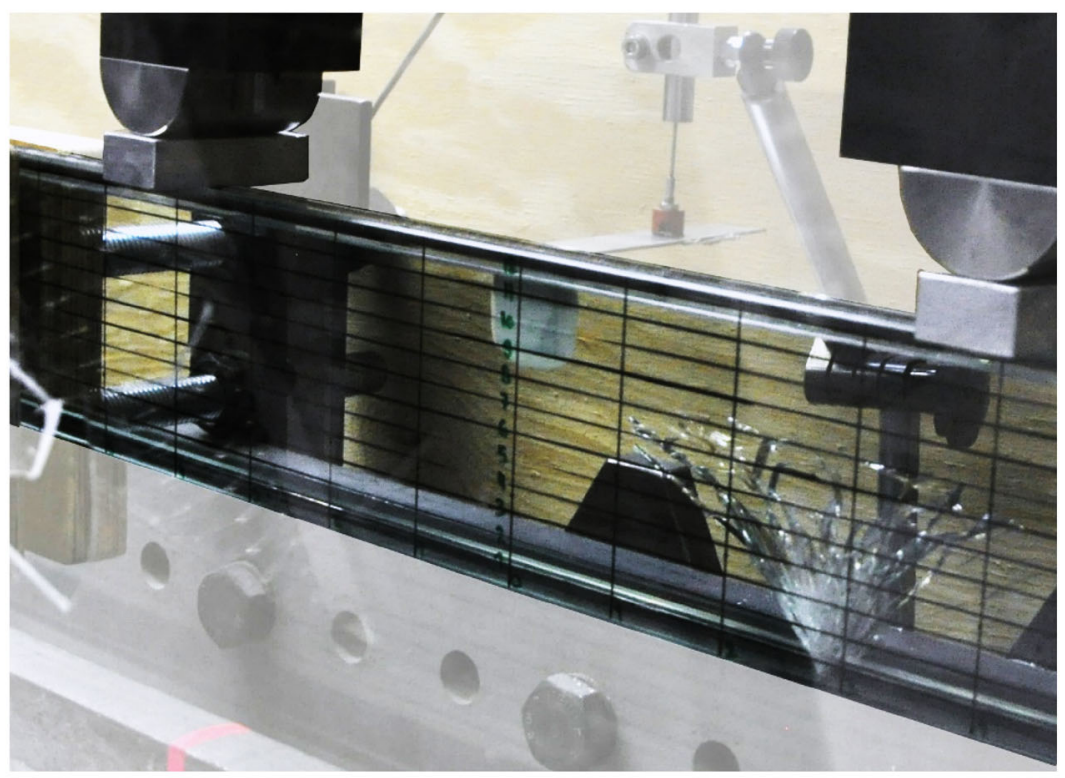

(b)

Fig. 9 a Deformed configuration at failure for the T8 beam (ABAQUS/Standard), front view $\left(u_{\max }=34.67 \mathrm{~mm}\right)$ and $\mathbf{b}$ photograph of post-tensioned beam experiments performed at EPFL $(\mathrm{CH})$, representing the typical failure configuration (Louter et al. 2014)
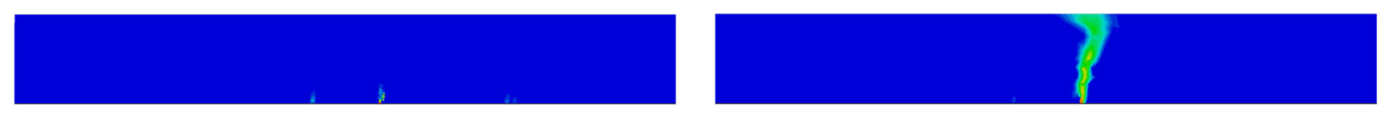

External glass layer

$\left(G_{I}\right)$
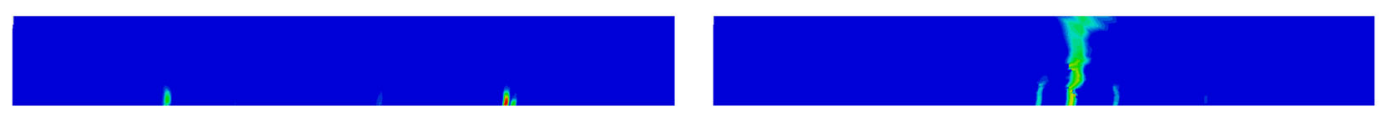

External glass layer

$\left(G_{2}\right)$
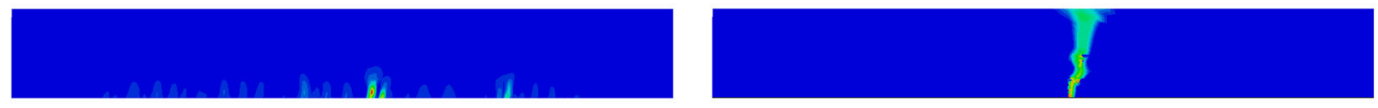

Middle glass layer

$\left(G_{3}\right)$

$$
u_{\max }=3.70 \mathrm{~mm}
$$

$u_{\max }=34.67 \mathrm{~mm}$

Fig. 10 Tensile damage propagation in the glass layers, T8 beam (ABAQUS/Standard). Undeformed geometrical configuration ('box detail' of Fig. 9a) 
Fig. 11 Tensile damage propagation in the external glass layer $\left(G_{2}\right)$ of the T8 beam (ABAQUS/Standard). Undeformed geometrical configuration ('box detail' of Fig. 9a)

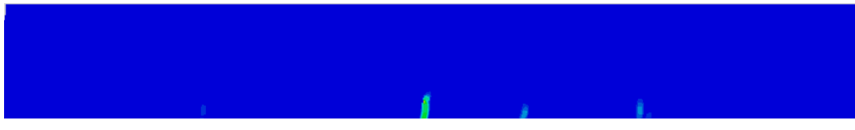

$u_{\max }=4.20 \mathrm{~mm}$

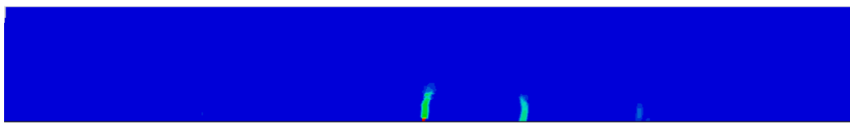

$u_{\max }=4.60 \mathrm{~mm}$

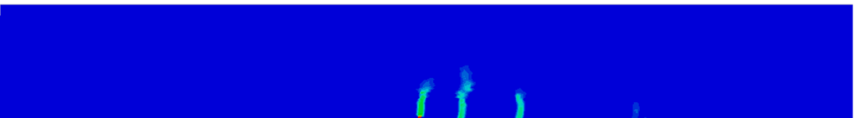

$u_{\max }=5.00 \mathrm{~mm}$

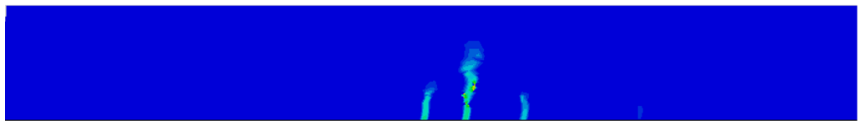

$u_{\max }=5.40 \mathrm{~mm}$

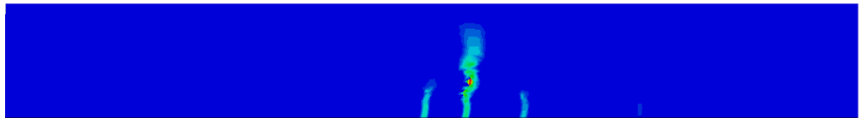

$u_{\max }=6.60 \mathrm{~mm}$

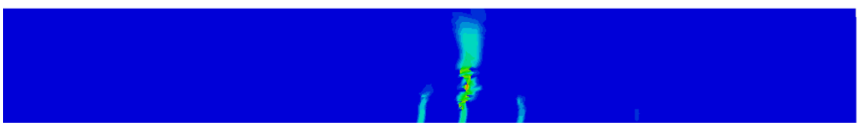

$u_{\max }=12.30 \mathrm{~mm}$

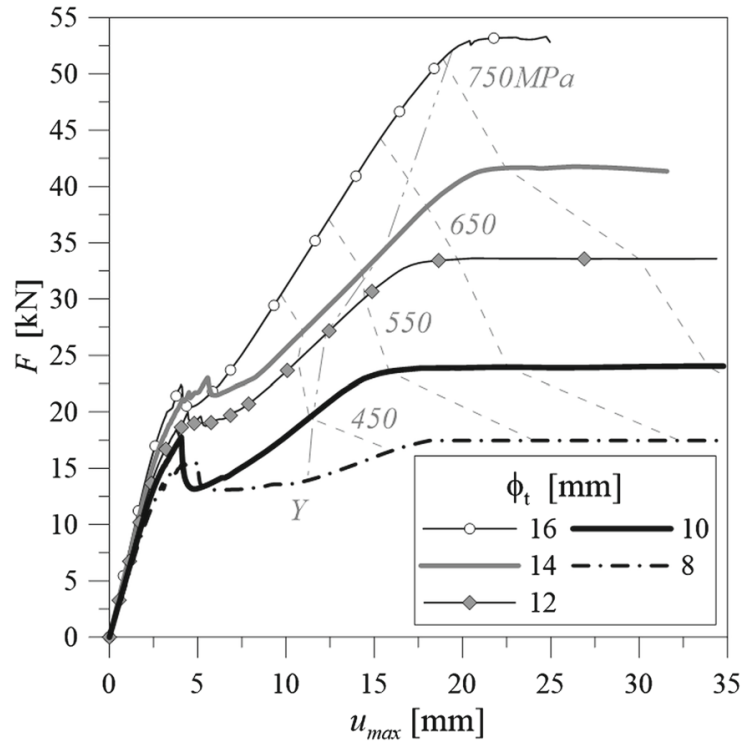

Fig. 12 Effects of the steel tendon percentage, with $P_{0}=50 \mathrm{kN}$ (ABAQUS/Standard)

in the form of $F-u_{\max }$ comparative plots, as well as in Table 2, where further key parameters derived from the same FE simulations are proposed. In that Table, two ratios $R_{t}$ and $R_{\sigma}$ are also emphasized. The first one, $R_{t}$, denotes the ratio between the total tendon area and the glass transversal cross-section $A_{\text {glass }}=2550 \mathrm{~mm}^{2}$. $R_{\sigma}$ represents the ratio between the assigned initial stress in each tendon (e.g. the tensile stress correspond- ing to $P_{0}$ ) and the yielding / ultimate stress of the same tendon.

Although a qualitatively comparable crack propagation and failure behaviour was shown for a large number of the tested geometrical configurations (see Sect. 4.2), this first parametric study emphasized several interesting aspects, both for the pre-cracked and post-cracked stages of the examined beam typology. As far as the same pre-compressive load $P_{0}$ was assigned to all the beams, the same initial compressive level was reasonably found for the glass layers at the end of Step I (e.g. see Fig. 7). The increase of the tendons nominal diameter $\phi_{t}$, however, manifested a rather appreciable variation of the beams stiffness and redundancy.

In the uncracked stage, a marked sensitivity of the beam elastic stiffness to the steel tendons diameter was noticed, compared to the reference unreinforced LG beam, see Table 2 . This latter value was calculated as the $F_{1}$ vs $u_{1}$ ratio, being $F_{1}$ the numerical first cracking load (e.g. the applied bending load leading the mid-span bottom edge of glass to the first attainment of maximum tensile stresses equal to the characteristic resistance value $\sigma_{R k}$ ) and $u_{1}$ the corresponding deflection.

Concerning the post-cracked stage an appreciable beneficial contribution of the steel tendons was further observed, leading to a marked increase of the expected maximum residual resistance $F_{u}$. However, as far as the steel tendon amount was increased, compared to the LG nominal section, the same FE simulations also 
Table 2 FE assessment of the steel tendon percentage (ABAQUS/ Standard), with $P_{0}=50 \mathrm{kN} \Delta=100 \times($ i-beam- 'no tendons')/'no tendons'

\begin{tabular}{|c|c|c|c|c|c|c|c|c|}
\hline$\phi_{t}(\mathrm{~mm})$ & $R_{t}$ & $R_{\sigma}$ & $\begin{array}{l}\text { Elastic stiffness } \\
F_{1} / u_{1}(\mathrm{kN} / \mathrm{mm})\end{array}$ & $\Delta(\%)$ & $\begin{array}{l}\text { Fracture } \\
\text { load } F_{1}(\mathrm{kN})\end{array}$ & $\begin{array}{l}\text { Fracture } \\
\text { displacement } \\
u_{1}(\mathrm{~mm})\end{array}$ & $\begin{array}{l}\text { Maximum } \\
\text { post-fracture } \\
\text { load } F_{u}(\mathrm{kN})\end{array}$ & $\Delta(\%)$ \\
\hline 16 & 0.0788 & 0.194 & 6.72 & 76.4 & 15.8 & 2.35 & 53.2 & 511.4 \\
\hline 14 & 0.0604 & 0.254 & 6.46 & 69.6 & 15.2 & 2.35 & 41.6 & 378.2 \\
\hline 12 & 0.0444 & 0.345 & 5.72 & 50.1 & 14.6 & 2.55 & 33.6 & 286.2 \\
\hline 10 & 0.0308 & 0.497 & 5.26 & 38.0 & 14.0 & 2.66 & 23.9 & 174.7 \\
\hline 8 & 0.0197 & 0.777 & 4.97 & 30.4 & 12.2 & 2.45 & 17.6 & 103.4 \\
\hline No tendons & - & - & 3.81 & - & 8.7 & 2.09 & $\mathrm{n} / \mathrm{a}$ & - \\
\hline
\end{tabular}

emphasized a decrease of the expected redundancy. This effect can be clearly noticed from Fig. 12, where a set of iso-curves representative of the first attainment of a fixed, conventional ultimate compressive stress at the glass top edge is drawn. The collected iso-curves, specifically, are provided for the 'ultimate' configurations associated to a glass compressive strength of 450 , 550,650 and $750 \mathrm{MPa}$ respectively. The aim of the collected iso-curves is to highlight that as far as the steel percentage increases, compared to the glass section, a certain decrease of redundancy should be expected. This aspect can be clearly seen from Fig. 12, hence suggesting that an appropriate balance of all the beam components is mandatory for optimal design purposes. A further iso-curve (' $\mathrm{Y}$ ') is also provided in Fig. 12, in order to highlight the instant in which a maximum tensile stress exceeding the yielding/ultimate resistance of steel is first attained in the bottom tendon. In this latter case, it can be seen that as far as the steel tendons section increases, the first yielding of the same tendons is postponed, compared to any possible crushing mechanism in glass. In this sense, it is clear from the proposed FE results that the amount of steel should be properly limited, compared to the reference glass section, in order to optimize both the pre-cracked and post-cracked stages, as well as to guarantee a certain collapse mechanism. At the same time, for a given tendon amount, a fundamental role is also expected from the assigned pre-stress level $P_{0}$, that should be properly calibrated.

\subsection{Initial pre-stress force $P_{0}$}

A second parametric study was carried out by varying, for a fixed geometrical configuration, the level of the

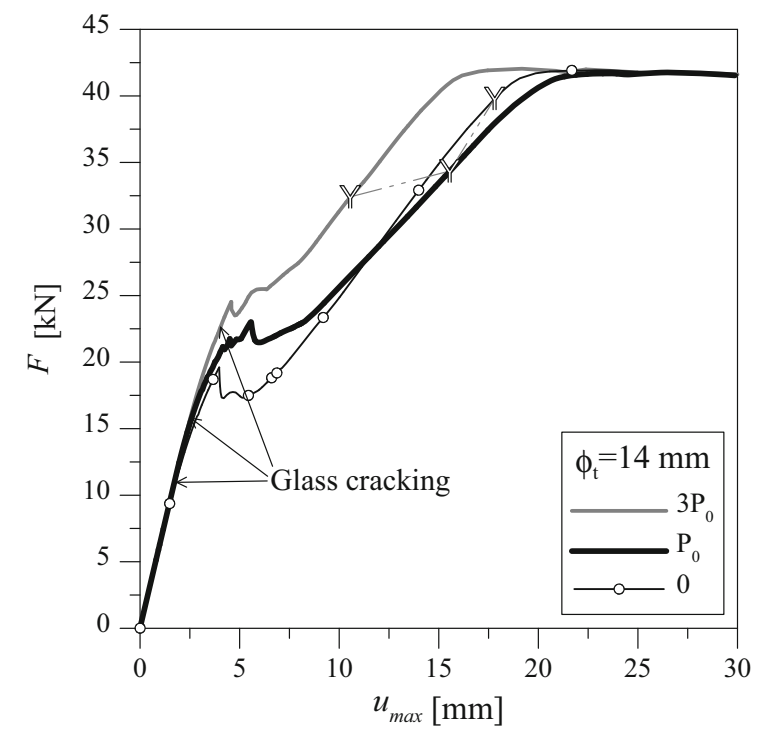

Fig. 13 Effects of the initial pre-stress force value $P_{0}$. Loaddisplacement bending response (ABAQUS/Standard)

initial pre-stressing force $P_{0}$. A practical example is proposed in Fig. 13 and Table 3, for a LG beam with a $14 \mathrm{~mm}$ tendon diameter, where the reference $P_{0}$ force is modified within 3 times the initial value and 0 (e.g. tendons without any pre-stress).

Also in this case, variations where found for the same beam geometry especially in the pre-cracked response, due to the different level of pre-stressing force $P_{0}$ applied to the tendons. The primary effect of a given $P_{0}$ value provides in fact a linear dependent variation of the initial compressive stresses in glass (with 0,18 and $62 \mathrm{MPa}$ the average value for the beams without pre-stress, with $P_{0}=50 \mathrm{kN}$ or $3 \mathrm{P}_{0}=150 \mathrm{kN}$ respectively), thus resulting in a dif- 
Table 3 FE assessment of the pre-stress level $P_{0}$ in the tendons (ABAQUS/ Standard) $\Delta=100 \times($ i-beam-'no tendons')/“No tendons'

\begin{tabular}{lllllllll}
\hline$\phi_{t}(\mathrm{~mm})$ & $P_{0}(\mathrm{kN})$ & $R_{t}$ & $R_{\sigma}$ & $\begin{array}{l}\text { Elastic stiffness } \\
F_{1} / u_{1}(\mathrm{kN} / \mathrm{mm})\end{array}$ & $\Delta(\%)$ & $\begin{array}{l}\text { Fracture } \\
\text { load } F_{1}(\mathrm{kN})\end{array}$ & $\begin{array}{l}\text { Fracture } \\
\text { displacement } \\
u_{1}(\mathrm{~mm})\end{array}$ & $\begin{array}{l}\text { Maximum } \\
\text { post-fracture } \\
\text { load } F_{u}(\mathrm{kN})\end{array}$ \\
\hline 14 & $3 \times 50$ & 0.0604 & 0.761 & 5.88 & 54.3 & 22.6 & 3.84 & 41.6 \\
\\
50 & 0.0604 & 0.254 & 6.46 & 69.6 & 15.2 & 2.35 & 378.2 \\
& 0 & 0.0604 & - & 6.48 & 70.0 & 10.7 & 1.65 & $\mathrm{n} / \mathrm{a}$ \\
\hline
\end{tabular}

ferent initial stiffness and first cracking configuration. In the same Fig. 13, the three arrows represent first glass cracking at the beam bottom edge for the models with null, $P_{0}$ and $3 P_{0}$ pre-stressing force respectively. Almost the same ultimate force $F_{u}$ was obtained for all the examined configurations, since this latter value is strictly related to the steel quantity only. As far as $P_{0}$ and the $R_{\sigma}$ ratio increase, however, the first yielding stress attainment in the bottom tendon is anticipated (see the ' $Y$ ' iso-curve of Fig. 13), hence compromising the overall available redundancy for the same beams.

\subsection{Initial geometrical imperfections and post-tensioning effects}

A final FE parametric study was then carried out by taking into account the effects of possible initial geometrical imperfections, with careful consideration especially for the post-tensioning and first-cracking phases. As far as the pre-stressing force $P_{0}$ is applied to a reference beam geometry, an almost uniform distribution of compressive stresses in glass is expected, with obvious effects in terms of bending response of the so posttensioned assembly. The presence of initial geometrical defects - either of small entity — could strongly affect the post-tensioning (and thus the full structural performance) of the same beam. It was shown for example in several past research projects, although strictly related to the lateral-torsional buckling performance of structural glass beams (see for example Belis et al. 2013; Bedon et al. 2015), the importance of an appropriate estimation of possible local/global effects due to initial geometrical curvatures (e.g. due to processing methods as well as material defects and/or load and boundary eccentricities).

\subsubsection{FE modeling assumptions ('Mshell' model)}

Before the execution of the FE studies, the feasibility and accuracy of a geometrically simplified model was assessed ('Mshell'). In this latter case, in accordance with Fig. 3, the original LG beam geometry was in fact described in the form of a monolithic cross-section with an equivalent thickness, as described later, and described in the form of 4-node shell elements (S4R type).

In doing so, careful consideration was paid to the mechanical calibration of the elastic mechanical properties of glass, being the $105 \times 22 \mathrm{~mm}^{2}$ monolithic section representative, in this specific case, of both the in-plane and out-of-plane bending / torsional properties of the physical LG section of Fig. 1. For this purpose, an equivalent, orthotropic material model was defined for the glass section. For the characterization of the in-plane bending stiffness, the same $E_{g}^{*}$ modulus defined in Sect. 3.3 was considered. In the case of the out-of-plane bending and torsional behaviour of the same monolithic cross-section, conversely, the calibration of the equivalent elastic mechanical properties for glass were defined by taking into account the concept of equivalent thickness $t_{e q}$ already in use for the lateral-torsional buckling analysis and verification of LG beams composed of 2 or 3 glass layers (see for example (Bedon and Amadio 2015) for the description of the full analytical model). In the latter case, in particular, the bending stiffness $E_{g} I_{x}$ of a given LG section can be calculated as:

$E_{g} I_{x}=E_{g} \frac{t_{e q}^{3} h}{12}$

where $t_{e q}$ depends on several geometrical and mechanical parameters like the beam cross-sectional dimensions and length, the glass/SG thicknesses and the shear modulus of the interlayers. In accordance with Sect. 3, 
Fig. 14 Reference geometrical imperfection shape for the parametric study (ABAQUS/Standard). a Axonometry and $\mathbf{b}$ top view (detail of the glass beam only). Scale factor for the deformed configuration $=50$

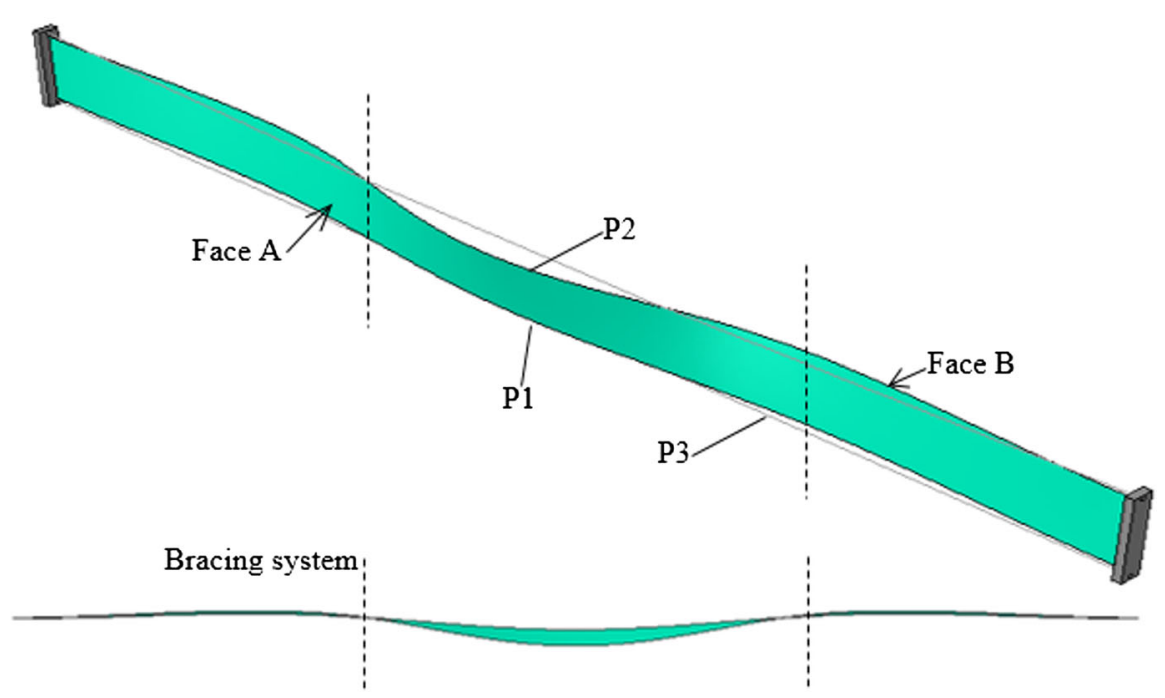

being the average duration of the experiments comprised between 30 and 45 minutes, the value $G_{S G}=$ $40 \mathrm{MPa}$ was taken into account, hence leading to $t_{e q}=$ $19.87 \mathrm{~mm}$. For the $105 \times 22 \mathrm{~mm}^{2}$ glassy shell FE model, based on Eq. ( 7 ), a correction factor $c_{g, x} \approx 0.73$ was taken into account for the $E_{g}^{*}$ modulus along the minor axis of the section.

In terms of torsional stiffness $G_{g} J_{t}$ of the same LG assembly, conversely, the torsional contributions of the three glass layers and the interposed SG foils should be taken into account, being this further stiffness dependent on both the geometrical features of the LG crosssection as well as sensitive to the $G_{S G}$ value. As in the case of the main longitudinal elastic Young's moduli, an equivalence was imposed between the actual $G_{g} J_{t}$ stiffness of the LG beam and the torsional stiffness of the monolithic $105 \times 22 \mathrm{~mm}^{2}$ shell section, hence leading to a further correction factor $c_{g, t o r} \approx 1.47$, to be accounted for the $G_{g}$ modulus of glass.

Based on Fig. 3a, the structural interaction between the (i) to (iii) model components, as well as the mechanical calibration of materials, the mesh pattern and the general FE solving method were then implemented as discussed in Sect. 3. The exception was represented by the glass (i) to end supports (ii) interaction, where at the interface between the shell glass beam and the solid steel supports, a 'shell-to-solid' coupling was used to reproduce a fully rigid connection with null relative displacements or rotations.

Compared to the original full 3D solid model, the assumption of a glass beam composed of shell elements only resulted in a marked optimization of the 'Mshell' model, e.g. being this latter characterized by a total number of $\approx 6,300$ elements and $\approx 38,000$ DOFs.

Both the Step I (post-tensioning stage) and II (bending test) were carried out on the 'Mshell' models in the same way of the full 3D assemblies. In order to validate the 'Mshell' concept, the T8 beam (with $P_{0}=50 \mathrm{kN}$ ) was first preliminary investigated. A rather interesting correlation with the corresponding experimental and full 3D numerical predictions was found.

\subsubsection{Solving approach and discussion of results}

In absence of further experimental measurements and geometrical details, as also recommended in (Belis et al. 2013 or Bedon et al. 2015), the effects due to possible initial geometrical imperfections were preliminary taken into account for the examined posttensioned beams in the form of fundamental buckling shapes derived from preliminary eigenvalue simulations. In this sense, the pre-cracked bending performance of each post-tensioned beam was investigated by taking into account the following procedure:

- An eigenvalue simulation was first carried out on a given geometry, so that the fundamental buckling shape could be obtained. The typical reference configuration-due to the presence of the bracing system enabling any possible out-of-plane deformation-is proposed in Fig. 14

- Application of the initial geometrical imperfection to each post-tensioned assembly (with $u_{0}$ the 
assigned maximum out-of-plane amplitude of this imperfection, in accordance with Fig. 14)

- Introduction of the pre-stressing force $P_{0}$ to each preliminary deformed beam (e.g. 'Step I' described in Sect. 3.2)

- Four-point bending test simulation on each preliminary deformed, post-tensioned beam (e.g. 'Step II' described in Sect. 3.2). In this case, the 'Step II' was manually stopped at the first tensile damage occurrence.

In general, the performed FE simulations highlighted that the assigned initial curvatures can strongly affect the post-tensioning stage and thus the firstcracking configuration.

Once a given beam geometry subjected to a geometrical imperfection agreeing with Fig. 14, the introduction of a certain pre-stressing force $P_{0}$ in the tendons provides a certain modification of the glass beam configuration, hence a sensible variation of the expected post-tensioning effects in glass. This effect was found to be dependent on a combination of multiple aspects, like the pre-stressing level, the imperfection amplitude as well as the out-of-plane bending stiffness of each glass beam. Careful consideration should consequently be paid for possible geometrical defects.

Some qualitative effects are emphasized by the comparative results collected in Figs. 15 and 16, as proposed for a T8 beam geometry $\left(P_{0}=50 \mathrm{kN}\right)$ subjected to initial curvatures of maximum amplitude $u_{0}$ equal to $L / 1000, L / 400$ (Belis et al. 2011) and $L / 300$. The same configurations are compared with the performance of the undeformed beam geometry $\left(u_{0}=0\right)$. Figure 15, in particular, highlights the distribution of initial compressive stresses in glass, due to $P_{0}$ only (e.g. end of 'Step I'). As far as an increasingly imperfection amplitude $u_{0}$ is assigned, it can be seen that a nonuniform distribution of compressive stresses in glass is found both along the beam length as well as through the beam thickness, due to a combination of posttensioning effects and imposed out-of-plane deformations. In the same Figure, the compressive stresses in glass are in fact separately proposed for the Faces A and $\mathrm{B}$ of each glass beam, identified in accordance of Fig. 14.

A more accurate analysis of the so obtained initial compressive stresses was also carried out for the same configurations, by taking into account three control points only, positioned at the mid-span cross-section (bottom/top glass edges) and at a distance $\approx L / 3$ from the beam ends (see Fig. 14, points P1-P3). These control points were chosen since associated to maximum out-of-plane deformations (P1 and P2) or to maximum bending curvatures respectively (P3), and thus strictly related to the attainment of highest principal stresses in glass. In accordance with Fig. 16, where the compressive stresses in glass due to $P_{0}$ are proposed (e.g. end of 'Step I'), an almost linear correlation was found between the amplitude $u_{0}$ of the assigned initial geometrical imperfections and the corresponding variation of stresses, with both positive and negative effects on the glass surfaces (Faces A and B defined in accordance with Fig. 14).

It is interesting to notice, in particular, that as far as the maximum amplitude $u_{0}$ of the imperfection increases, the pre-compressive effect can be fully disregarded in certain configurations, as a combined effect of imposed out-of-plane deformations and redistribution of stresses/out-of-plane deflections due to $P_{0}$ (see for example 'P1-A' and 'P2-A' in Fig. 16a). A premature glass fracture, consequently, can be reasonably expected either in presence of relatively small geometrical defects. A variation in the propagation of tensile damage in glass and in the portion of the beam subjected to the opening of major cracks (e.g. compared to Fig. 10 and 11) can also be expected.

In this sense, a last comparative analysis of results was carried out on the same beam configurations discussed in Figs. 15 and 16a. FE data and plots are proposed in Figs. 16b and 17 for the bending performance of some selected scenarios, up to first tensile damage initiation. Figure 16b, specifically, presents the maximum principal stresses in glass for the $\mathrm{T} 8$ beam with $u_{0}=L / 300$, as obtained from the control points P1 and P3 on the Faces A and B. Figure 17 proposes, for the same cases, the tensile damage initiation (with blue color for fully uncracked glass).

In the case of the undeformed beam $\left(u_{0}=0\right)$, a uniform distribution of principal stresses is found through the beam thickness, and this effect is also in agreement with the distribution of cracks obtained separately for each glass layer, based on 3D simulations (e.g. Figs. 10 and 11). The beam bottom edge first cracks at $F=11.9 \mathrm{kN}$, see Figs. $16 \mathrm{~b}$ and 17 .

When an initial curvature is assigned (e.g. $u_{0}=$ $L / 300$, in this example), the curvature effect manifests in a premature glass cracking at mid-span $(F=$ $8.7 \mathrm{kN}$, Face A), and the progressive damage propaga- 

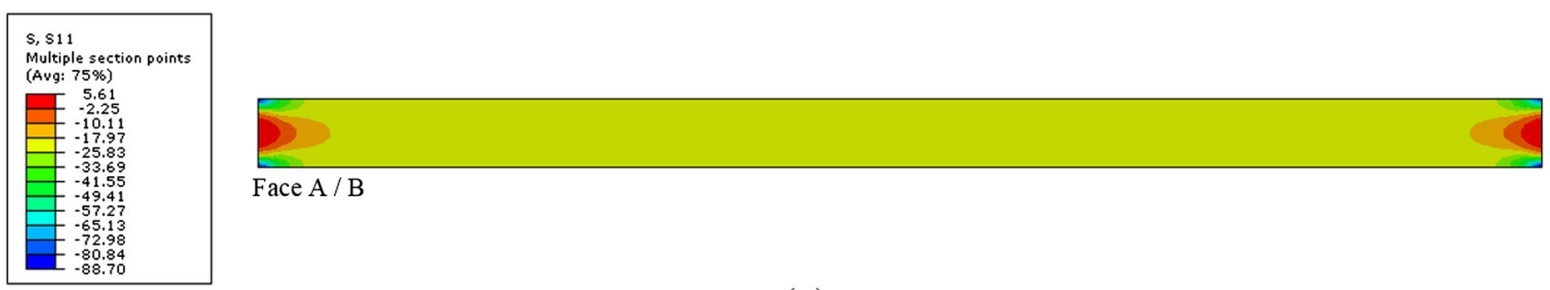

Face A / B

(a)
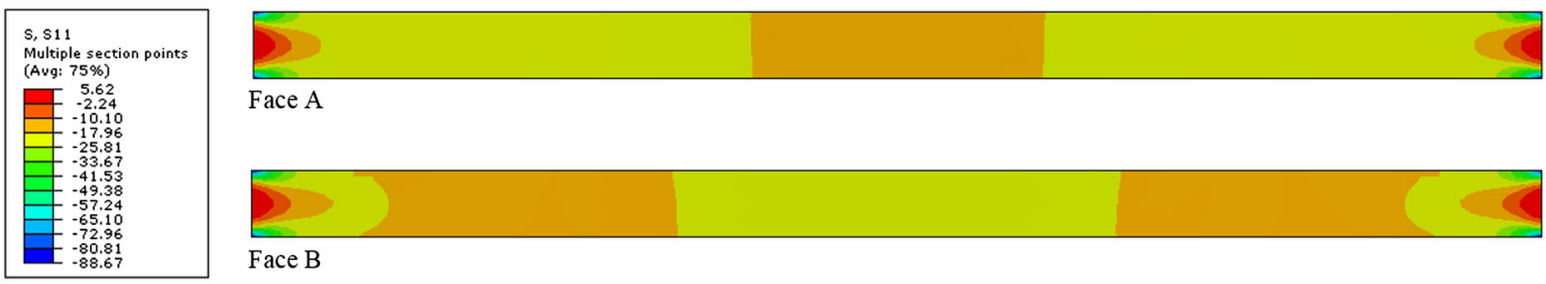

Face A

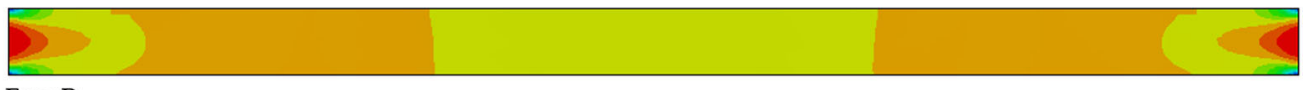

Face B

(b)
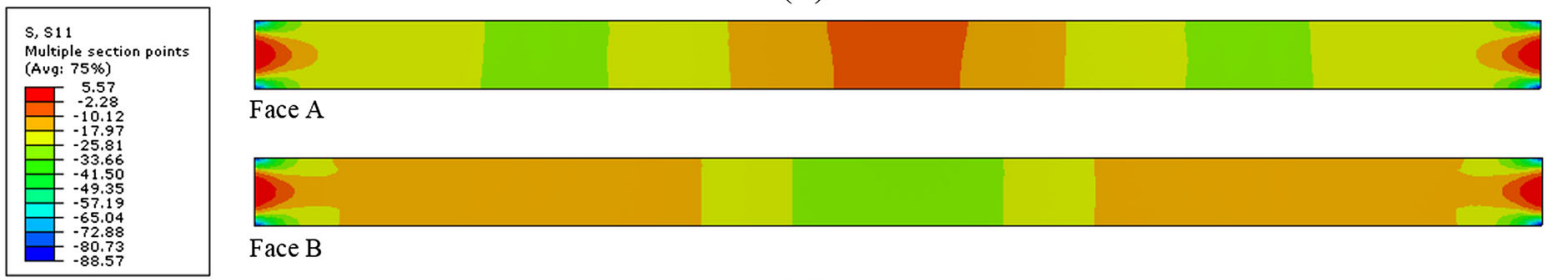

Face A

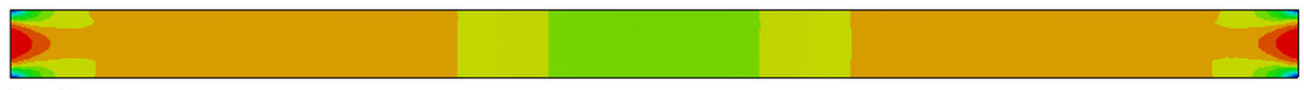

Face B

(c)
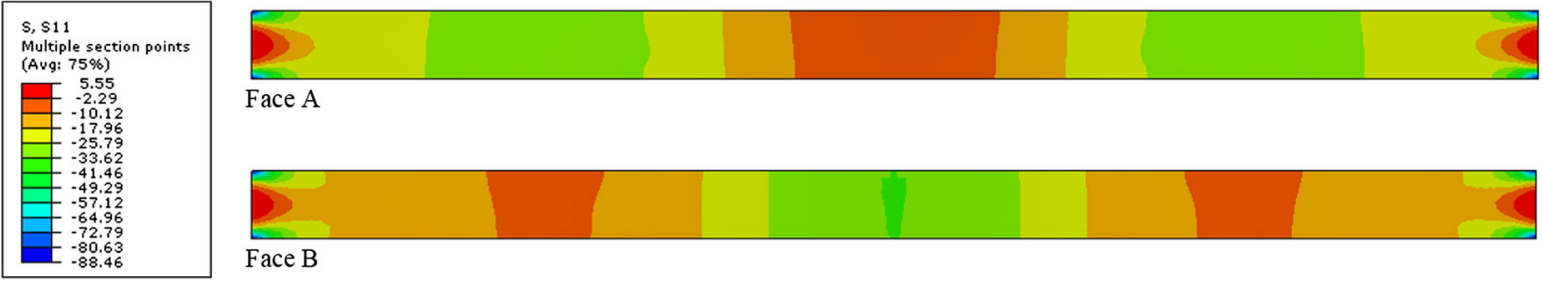

Face A

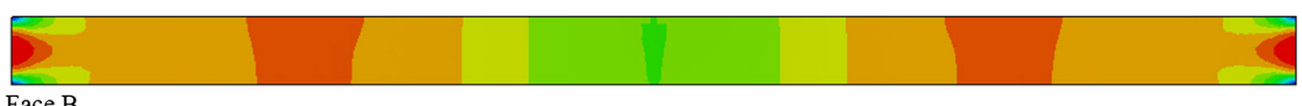

Face B

Fig. 15 Numerically calculated initial compressive stresses in glass (values in $[\mathrm{MPa}]$ ) for the T8 beam geometry, as a function of the maximum amplitude $u_{0}$ of the initial geometrical imperfections, with $P_{0}=50 \mathrm{kN}$ (ABAQUS/Standard, 'Mshell'). a $u_{0}=0 ; \mathbf{b} u_{0}=L / 1000 ; \mathbf{c} u_{0}=L / 400$ and $\mathbf{d} u_{0}=L / 300$. Undeformed geometrical configuration (front view) tion affects the portion of the beam close to the bracing system also (see Fig. 17, $F=12.5 \mathrm{kN}$, Face B).

Through the full parametric study, the analyses highlighted that the presence of initial geometrical defects does not affect the in-plane bending stiffness of the beams. This finding can be also derived from Fig. 16b, where the collected plots (both for the undeformed and initially imperfect beams) have almost the same slope. A significant decrease of the first cracking load $F_{1}$, due to the same initial geometrical imperfections, should be however properly taken into account.

The effect of lateral restraints (e.g. the bracing system implemented in the test setup, in this example) should also be properly assessed, in view of a further detailed investigation of the structural performance of the examined structural typology. In any case, the discussed FE studies generally highlighted the high potentiality of the design concept.

\section{Conclusions}

In this paper, the structural performance of posttensioned laminated glass beams with mechanically anchored external tendons has been investigated by means of extended finite-element (FE) numerical sim- 


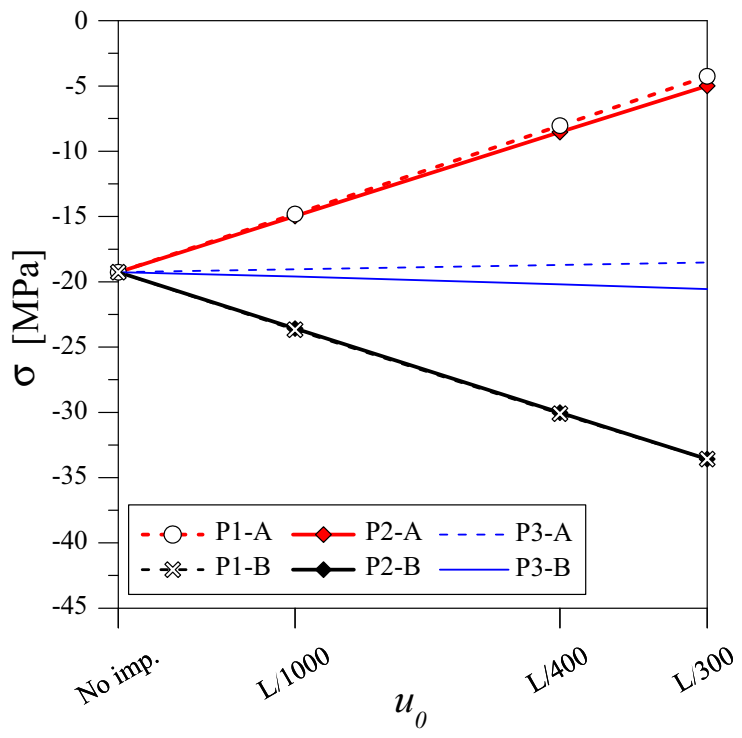

(a)

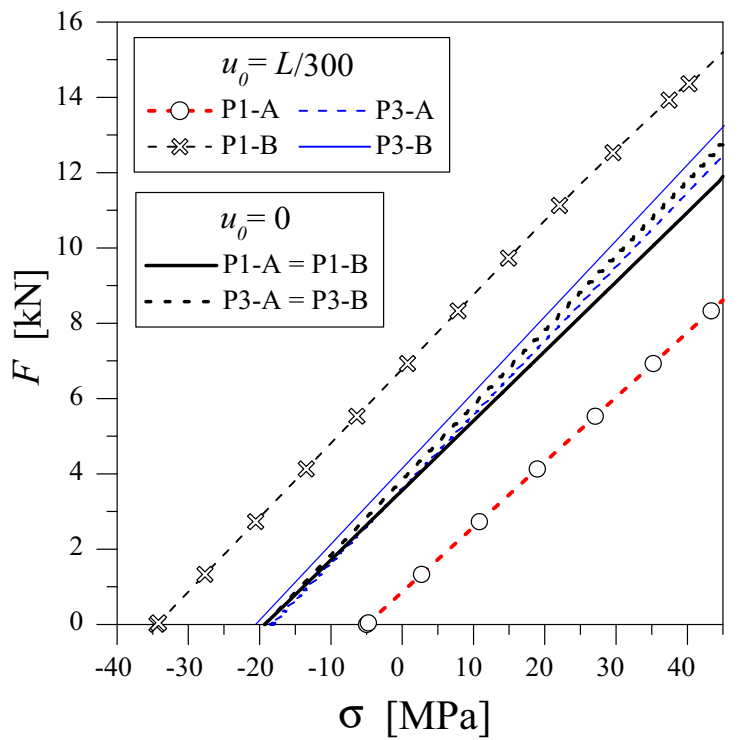

(b)

Fig. 16 Effect of initial geometrical imperfections of maximum amplitude $u_{0}$ : a amount of compressive stresses in glass due to the pre-stressing force $P_{0}$ only and $\mathbf{b}$ pre-cracking load-stress bending response (ABAQUS/Standard, 'Mshell')

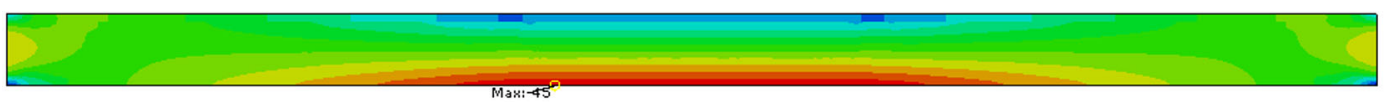

Faces A and B

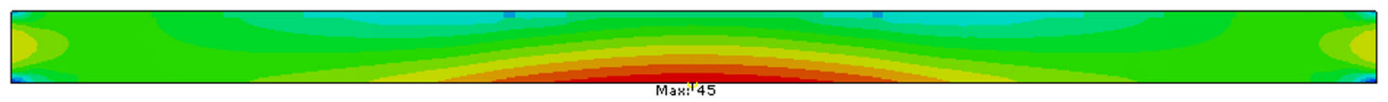

Face A

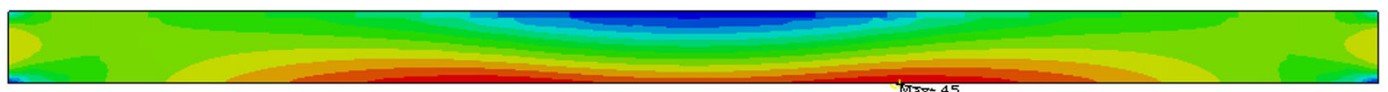

Fig. 17 Effect of initial geometrical imperfections of maximum amplitude $u_{0}$ on the initiation of tensile damage in glass (ABAQUS/Standard, 'Mshell'). Contour-plot of maximum prin-

ulations. Careful consideration has been paid, through the FE parametric study, to the appropriate mechanical and geometrical calibration of each beam component, as well as their reciprocal interaction when subjected to bending loads at room temperature.

First, a full 3D solid model has been implemented and validated towards the full-scale experimental results derived from past research projects, for the same beam typology. The mechanical calibration of the SG foils, specifically, was carried out on the base of the experimental conditions (i.e. time loading and temper- cipal stresses in glass at the first crackling configuration (values in $[\mathrm{MPa}]$, front view, undeformed geometry)

ature). In this sense, as a further extension of the current research study, additional FE investigations should also assess the effects of different strain rates and temperatures on the structural performance of the same structural typology. As shown in the paper, however, an interesting correlation was found between the compared numerical and experimental data, hence suggesting the extension of the FE study to a multitude of parameters of practical interest for the full development and optimization of this novel design concept. The effects of (1) several percentage amounts of tendons, as well as 
(2) the level of the imposed post-tensioning force and (3) the influence of possible initial geometrical imperfections on the post-tensioning process and effects (with careful consideration for the elastic/first-cracking performance of some selected configurations), have been properly investigated. In the latter case, the FE study has been carried out by means of a computationally efficient, geometrically simplified but accurate shell model.

In general, the FE studies highlighted that the examined design concept can offer appreciable resistance and redundancy potentialities. Several mechanical and geometrical aspects should be properly taken into account, however. The investigations highlighted for example that the presence of possible initial geometrical curvatures, although providing the same in-plane bending stiffness as in the case of initially fully undeformed beams, can strongly affect the compressive stress distribution in glass due to the post-tensioned tendons, hence minimizing the effects of the same posttensioning mechanism and resulting in a premature glass fracture. At the same time, the effects deriving from local phenomena (i.e. glass edge strength, load introduction, glass-to-steel contacts, etc.) should be also properly explored.

It is thus expected, based on the discussed FE study, that practical rules could be derived for a further refinement and development of the post-tensioned glass beam concept.

Conflict of interest The authors state that there is no conflict of interest.

\section{Annex I}

ABAQUS/Standard input parameters for the mechanical description of the post-cracked behavior of glass.

Tensile mechanical behavior:

${ }^{*}$ Concrete Tension Stiffening, type GFI, with $\sigma_{t}=$ $45 \mathrm{MPa}$ the tensile resistance of glass and $G_{f}=3 \mathrm{~J} / \mathrm{m}^{2}$ the fracture energy

*Concrete Tension Damage, type DISPLACEMENT, with maximum tensile damage $d_{t}=0.8$ at $u_{c k, t}=$ $2 G_{f} / \sigma_{t}=1.33 \times 10^{-4} \mathrm{~mm}$

$w_{c}=0$ (no compression recovery)

Compressive mechanical behavior:
$*$ Concrete Compression Hardening, $\sigma_{c}=1000 \mathrm{MPa}$ the compressive resistance

*Concrete Compression Damage, type DISPLACEMENT, with maximum compressive damage $d_{c}=0.8$ at $u_{c k, c}=u_{c k, t}$ $w_{t}=0$ (no tension recovery)

\section{References}

Bedon, C., Amadio, C.: Design buckling curves for glass columns and beams. Struct. Build. 168(7), 514-526 (2015)

Bedon, C., Belis, J., Amadio, C.: Structural assessment and lateral-torsional buckling design of glass beams restrained by continuous sealant joints. Eng. Struct. 102, 214-229 (2015)

Bedon, C., Louter, C.: Exploratory numerical analysis of SGlaminated reinforced glass beam experiments. Eng. Struct. 75, 457-468 (2014)

Belis, J., Bedon, C., Louter, C., Amadio, C., Van Impe, R.: Experimental and analytical assessment of lateral torsional buckling performance of laminated glass beams. Eng. Struct. 51, 295-395 (2013)

Belis, J., Mocibob, D., Luible, A., Vandebroek, M.: On the size and shape of initial out-of-plane curvatures in structural glass components. Constr. Build. Mater. 25, 2700-2712 (2011)

Bos, F.P., Veer, F.A., Hobbelman, G.J., Louter, P.C.: Stainless steel reinforced and post-tensioned glass beams. In: 12th international conference on experimental mechanics, pp. 1-9. Politecnico di Bari, Bari (2004)

Callewaert, D., Belis, J., Delincé, D., Van Impe, R.: Experimental stiffness characterisation of glass/ionomer laminates for structural applications. Constr. Build. Mater. 37, 685-692 (2012)

CNR-DT 210/2013: Istruzioni per la progettazione, l'esecuzione ed il controllo di costruzioni con elementi strutturali in vetro [Technical Document, in Italian], National Research Council, Rome (2013)

Díaz, M.A.N.N., Miguel, J.M.C., Aguirregabiria, B.L.: Prestressed glass beams, pp. 645-649. Glass Performance Days, Glaston Finland Oy, Tampere (2011)

EN 572-2:2012: Glass in building. Basic soda lime silicate glass products (2012)

Ferretti, D., Rossi, M., Royer-Carfagni, G.: Through cracked tensile delamination tests with photoelastic measurements. In: Proceedings of challenging glass 3, pp. 641-652, TU Delft (2012)

Franz, J.: Untersuchungen zur Resttragfähigkeit von gebrochenen Verglasungen. Technische Universität Darmstadt. PhD-thesis (2015)

Gattesco, N., Amadio, C., Bedon, C.: Experimental and numerical study on the shear behaviour of stone masonry walls strengthened with GFRP reinforced mortar coating and steel-cord reinforced repointing. Eng. Struct. 90, 143-157 (2015)

Jordão, S., Pinho, M., Martins, J.P., Santiago, A., Neves, L.C.: Behaviour of laminated glass beams reinforced with prestressed cables. Steel Constr. 7(3), 204-207 (2014) 
Larcher, M., Solomos, G., Casadei, F., Gebbeken, N.: Experimental and numerical investigation of laminated glass subjected to blast loading. Int. J. Impact Eng. 39, 42-50 (2012)

Lee, J., Fenves, G.L.: Plastic-damage model for cyclic loading of concrete structures. J. Eng. Mech. 124(8), 892-900 (1998)

Louter, C., Cupac, J., Lebet, J.P.: Exploratory experimental investigations on post-tensioned structural glass beams. J. Façade Design Eng. 2, 3-18 (2014)

Louter, C., Nielsen, J.H.: Numerical analyses of the effect of SG-interlayer shear stiffness on the structural performance of reinforced glass beams. In: Proceedings of COST action TU0905 mid-term conference on structural glass, pp. 405412 (2013)

Lubliner, J., Oliver, J., Oller, S., Onate, E.: A plastic-damage model for concrete. Int. J. Solids Struct. 25(3), 299-326 (1989)

Martens, K., Caspeele, R., Belis, J.: Development of composite glass beams: a review. Eng. Struct. 101, 1-15 (2015a)

Martens, K., Caspeele, R., Belis, J.: Development of reinforced and posttensioned glass beams: review of experimental research. ASCE J. Struct. Eng. (2015b). doi:10.1061/ (ASCE)ST.1943-541X.0001453
Pandey, A.K., Bisht, R.S.: Numerical modelling of infilled clay brick masonry under blast loading. Adv. Struct. Eng. 17(4), 591-606 (2014)

Ringli, R., Vogel, T.: Load-bearing behavior of spliced glass beams under bending action. Glass Struct. Eng. doi:10. 1007/s40940-016-0006-5 (2016)

Trösch, E.: Tragverhalten von überlappend laminierten Verbundglasträgern für grosse Spannweiten. PhD-thesis, ETH Zürich (2015)

Schober, H., Gerber, H., Schneider, J.: Ein Glashaus für die Therme in Badenweiler. Stahlbau 73, 886-892 (2004)

Simulia: ABAQUS/Standard computer software, v.6.12 (2016)

Vandebroek, M., Belis, J., Louter, C., Van Tendeloo, G.: Experimental validation of edge strength model for glass with polished and cut edge finishing. Eng. Fract. Mech. 96, 480489 (2012)

Weller, B., Engelmann, M.: Spannglasträger-Glasträger mit vorgespannter Bewehrung. Glasbau 83(1), 193-203 (2014)

Xiong, X.Y., Xue, R.J., Zhang, S., Wang, L.J.: The finite element analysis on seismic performance of ring beam and constructional column with different storey in masonry building. Adv. Mater. Res. 919-921, 1016-1019 (2014) 